\title{
DISTRIBUCIÓN DEL OXígENO DISUELTO EN LA ZONA OESTE DE LA CONVERGENCIA SUBTROPICAL DEL ATLANTICO SUD
}

\author{
(Recebido en 24/5/1967)
}

\author{
Mariano Javier Pizarro *
}

\begin{abstract}
SYNOPSIS
The distribution of oxygen in an area of the South Atlantic Ocean has been studied. The area is limited by the Argentinian continental slope and the $45^{\circ} \mathrm{W}$ meridian and from $35^{\circ} \mathrm{S}$ to $47^{\circ} \mathrm{S}$. The distribution of oxygen in studied in relation with the salinity distribution in seven horizontal levels and one vertical profile. The oxygen distribution in the area of the Subtropical Convergence has a characteristic pattern that seems to be very useful in the determination of the Convergence.

The Subtropical Convergence was situated between the oceanographic station where was found the maximum salinity and the maximum oxygen (negative) horizontal gradients. The maximum fluctuation of the Subtropical Convergence area is situated immediately East of Malvinas Current, where its desplacement $\mathrm{N}-\mathrm{S}$ between winter and spring is, at least, 200 nautical miles.

The water sunk at the Subtropical Convergence can be followed by its oxygen content. The intermediate maximum of oxygen is not coincident with the depth of salinity minimum characteristic of the nucleos of S. A. waters. A hipothesis to explain this is given.
\end{abstract}

\section{INTRODUCCIÓN}

La distribución del oxígeno disuelto en al agua del mar está vinculado a importantes procesos de circulación y mezcla. Las relaciones que existen entre esta variable oceanográfica y las actividades biológicas que tienen lugar en el medio marino, hacen que el estudio de la distribución del oxígeno disuelto sea de considerable importancia.

El esquema circulatorio general en el Atlántico Sud ha sido dilucidado en líneas generales como resultado de los estudios de los oceanográfos como Wüst, Deacon, Defant, Seiwell etc, que utilizaron las informaciones que, sobre la distribución de variables físicas y químicas, fueran recogidas durante las grandes campañas oceanográficas del 'Meteor', 'Discovery', 'Challenger' etc. No obstante, hay ciertas áreas donde tienen lugar variaciones estacionales muy amplias que obligan a un estudio más detallado. Una de ellas es el área de la Convergencia Subtropical, que se extiende a todo lo ancho del Océano Atlántico entre los $35^{\circ}$ y $45^{\circ} \mathrm{S}$. Se origina fuera de la plataforma continental argentina como resultado del encuentro de dos masas de agua, las aguas subantárticas y las aguas subtropicales.

- Dirección actual: Estación de Biologia Marina de Montemar - Casilla 13-D, Viña del Mar, Chile.
En este trabajo nos ocuparemos de la distribución de oxígeno en el extremo oeste de la Convergencia Subtropical, en relación con las masas de agua que toman parte en el proceso.

La información que hemos utilizado fué obtenida durante las campañas oceanográficas Tridente I y II. Estas campañas fueron programadas en la primera reunión de la Comisión Oceanográfica Interguvernamental que tuvo lugar en Paris en Octubre de 1961, en esa oportunidad, Argentina, Brasil y Uruguay, acordaron a través de sus respectivos servicios hidrográficos, efectuar un estudio conjunto de las condiciones oceanográficas de la zona oeste del Atlántico Sud desde Cabo Frio hasta los $50^{\circ}$ de S. Estas campañas se iniciaron en Agosto de 1962 con la TRIDENTE I, en Diciembre del mismo año se realizó la campaña TRIDENTE II. Para este trabajo hemos utilizado fundamentamente los datos provenientes del área oceánica cubierta por el Servicio de Hidrografia Naval de Argentina y algunas estaciones ocupadas por los buques de la Armada de Brasil. En los cuadros I y II se indican las posiciones de las estaciones utilizadas para este trabajo y en las Figuras 1 y 2, la posición de las mismas. 


\section{1 - Hidrologia de la Zona}

La Zona Subantártica, se extiende desde el norte de la Convergencia Antártica hasta la Convergencia Subtropical. Las aguas oceánicas que ocupan esta área se denominan Aguas Subantárticas. Se extienden desde la superficie hasta una profundidad de unos 1.000 metros. Tienen su origen en la Convergencia Antártica. La formación de esta agua tipo, es un fenómeno general en todo el hemisferio y, de acuerdo con Deacon (1933), provienen de las aguas de superficie antártica que se hunden en la Convergencia Antártica; de mezcla superficial a través de la misma convergencia; de dilución debido a que en la zona subantártica las precipitaciones superan ampliamente a las pérdidas por evaporación y, de aportes de aguas superficiales de origen subtropical a través de la Convergencia Subtropical.

TABLA I - Posición y fecha en que se realizaron las estaciones oceanográficas de la Campaña TRIDENTE I (invierno)

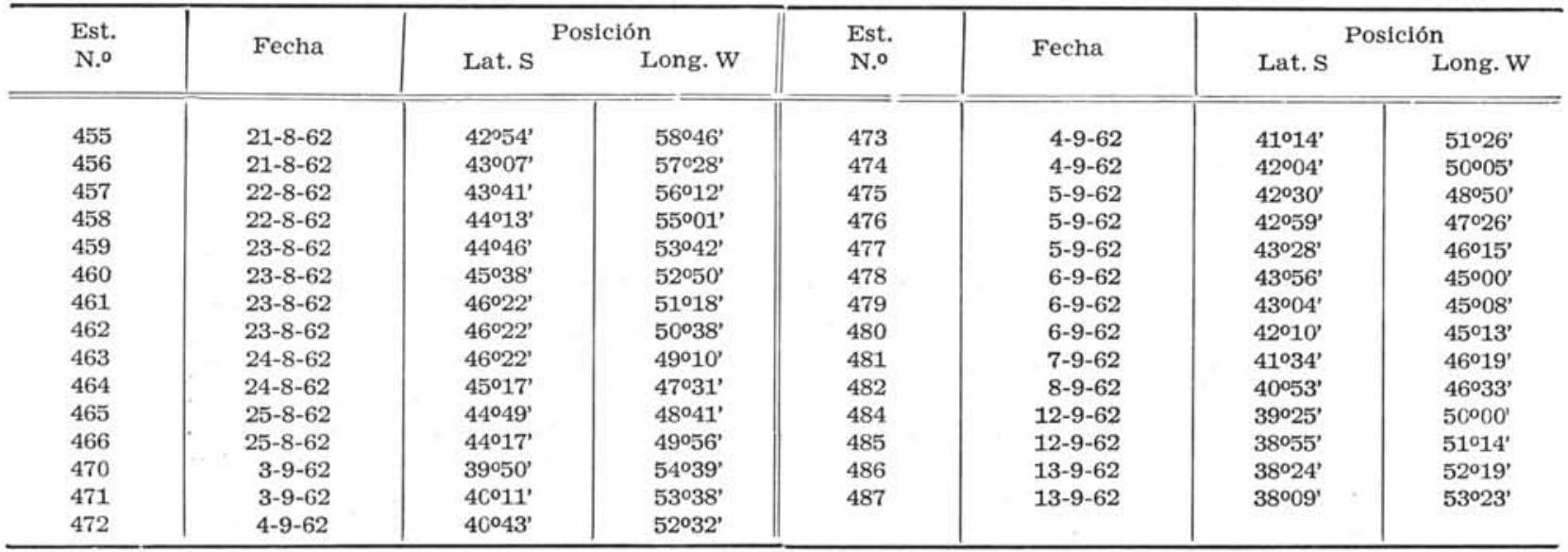

TABLA II - Posición y fecha en que se realizaron las estaciones oceanográficas de la Campaña TRIDENTE II (primavera)

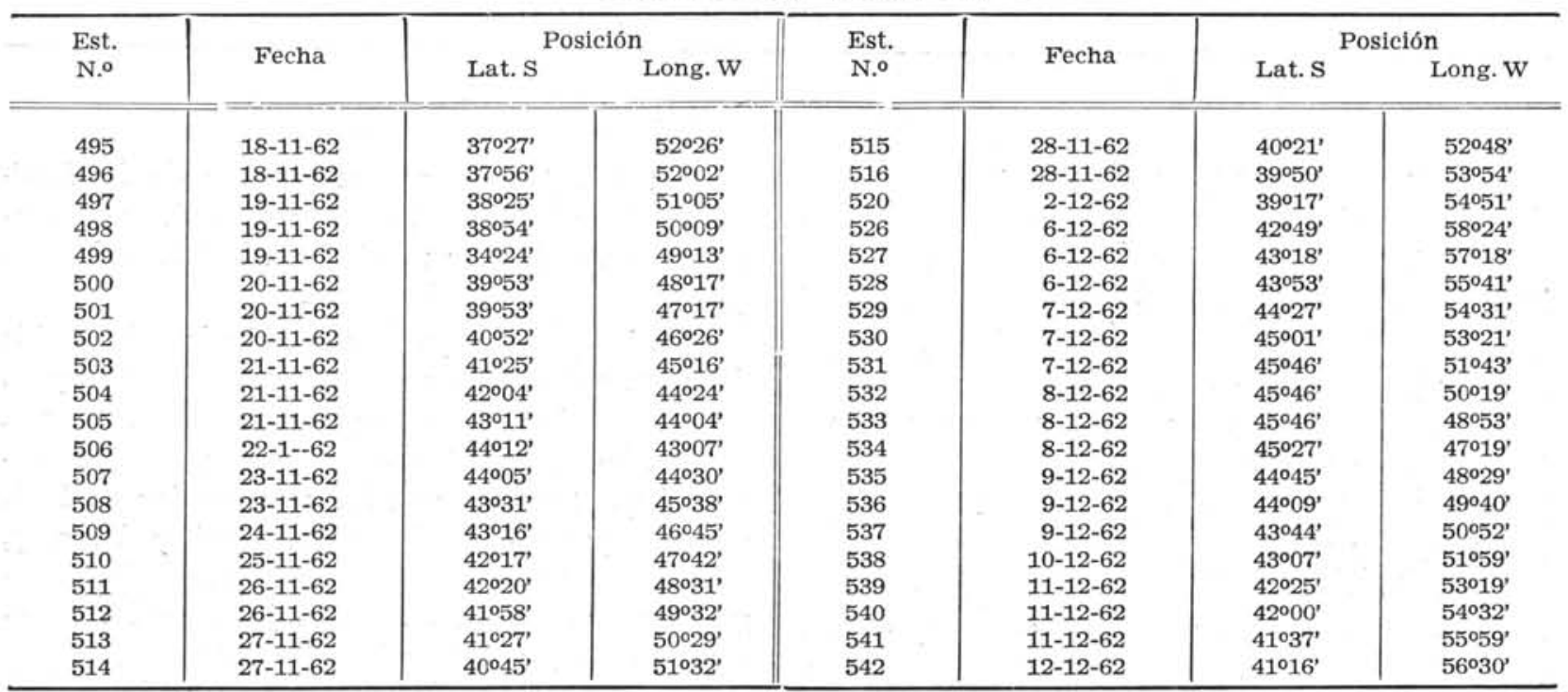

Las aguas subantárticas tienen una deriva hacia el norte, hundiendose por debajo de la superficie en la Convergencia Subtropical.

Al norte de esta zona pueden detectarse por una salinidad mínima a profundidades medias. La formación de las aguas subantárticas es muy intensa en el Océano Atlántico donde es posible detectarla aún al norte del Ecuador (Flugister, 1960).

Aunque la deriva hacia el norte del agua suban- tártica se produce a todo lo ancho del Oceáno Atlántico, inmediatamente al norte de la C.A., hacia los $50^{\circ} \mathrm{S}$, tiene, debido probablemente al efecto de Coriolis, una marcada preferencia por el costado oeste del Océano Atlántico Sur tomando el caracter de una corriente (Defant 1961, p. 678).

Fuera de la plataforma continental argentina, entre las latitudes de $47^{\circ}$ a $40^{\circ} \mathrm{S}$, se presentán bruscamente variaciones en espacio y tiempo de los facto- 
res oceanográficos. Estos se interpretan como consecuencia del encuentro de dos tipos muy diferentes de aguas.

En esta zona se origina la Convergencia Subtropical (C.St.), donde se encuentran las aguas subantárticas frias y poco salinas con las aguas subtropicales de la corriente de Brasil, cálidas y saladas.

En esta área de convergencia que se extiende hacia el Este a todo lo ancho del Océano Atlántico, tiene lugar en forma contínua el hundimiento de las aguas subantárticas por debajo de las aguas subtropicales más ligeras.

En este trabajo nos ocuparemos de esta área, limitada al oeste por el talud continental argentino y al este por el meridiano de $45^{\circ} \mathrm{W}$, y entre las latitudes de $47^{\circ}$ y $35^{\circ} \mathrm{S}$.

Las aguas subantárticas al norte de la C.St. se denomina Agua Antártica Intermedia (AAI) o bién Agua Intermedia, que se detecta por una salinidad mínima a profundidades alrededor de 1.000 metros (Menéndez \& Pizarro, 1965). Por debajo de las aguas intermedias, ya sea en la zona subantártica como al norte de la misma se presenta otra capa de agua de origen norte: se denomina Agua Cálida Profunda (ACP).

Wüst (1936) dió los siguientes valores para definir el núcleo de las aguas subantárticas, $33,80^{\circ} \%$ de salinidad y $2,2^{\circ} \mathrm{C}$ de temperatura, en sus orígenes. A $\operatorname{los} 10^{\circ} \mathrm{N}$ y a los 1.000 metros de profundidad cuando la capa AAI ha casi desaparecido o, en otras palabras, cuando la proporción del agua subantártica original en la mezcla es menor del $1 \%$, las características son: salinidad $34,95 \%$ y temperatura $6,6^{\circ} \mathrm{C}$. Para las aguas subtropicales, DEAcon (1933) ha dado las siguientes características, 35 a $36^{\circ} \%$ de salinidad y temperatura de 15,5 a $18^{\circ} \mathrm{C}$.

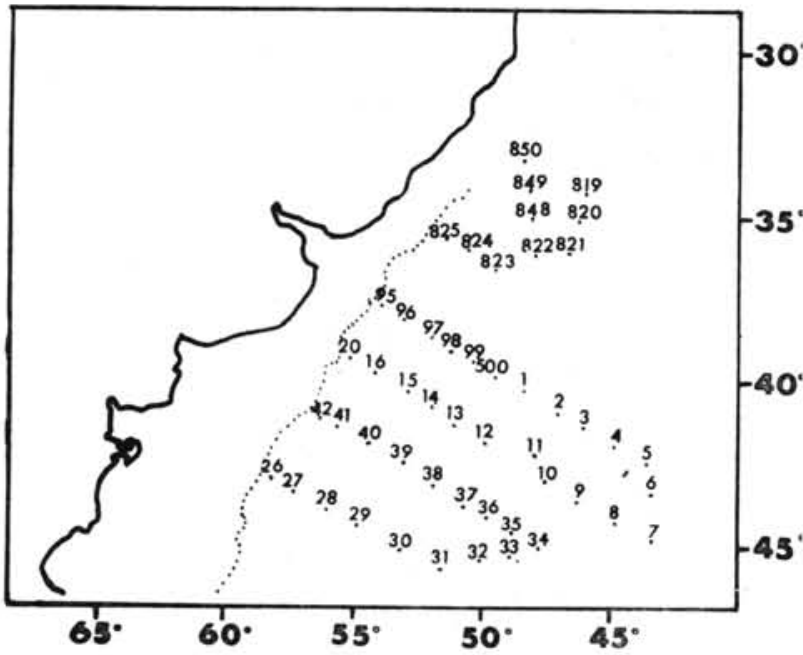

Fig. 1 - Muestra la posición relativa de las estaciones oceanográficas ocupadas en invierno.

Teniendo en cuenta que masa de agua es un concepto que se define en base a salinidad y temperatura $y$, que estas dos variables son conservativas, es posible determinar cual es la proporción de un componente original en una mezcla cuando se conoce los valores límites entre los cuales la masa de agua está aún definida.

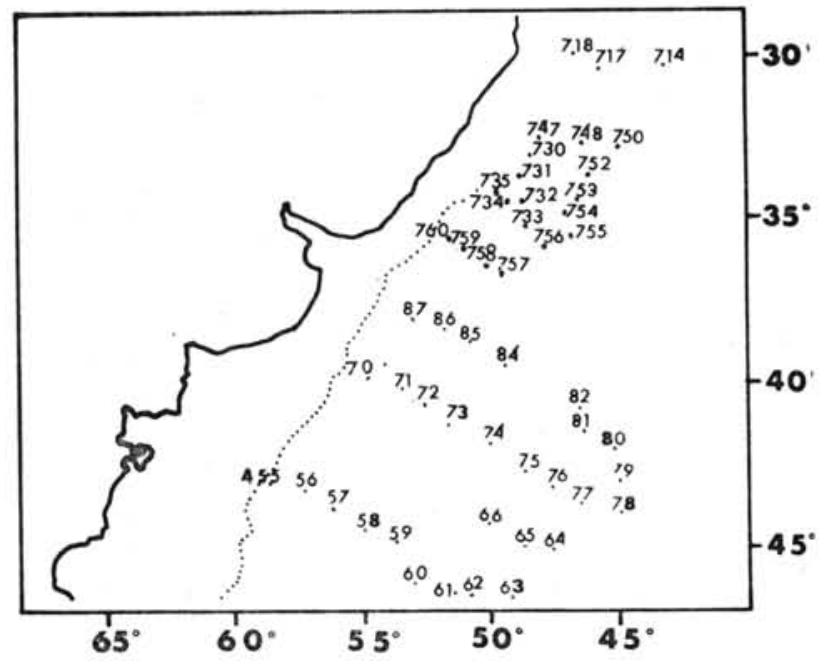

Fig. 2 - Muestra la posición relativa de las estaciones oceanográficas ocupadas en primavera.

Teniendo en cuenta estos hechos, Wüst (1936) determinó una curva que permite calcular el porcentaje de agua subantártica original en el nucleo de esta capa, tomando como valores límites las características del núcleo en sus orígenes, inmediatamente al norte de la C.A. $\left(33,80^{\circ} \%\right.$ de salinidad y $2,2^{\circ} \mathrm{C}$ de temperatura a 300 metros de profundidad) $\mathrm{y}$, al final de la capa a los $10^{\circ} \mathrm{N}\left(34,95^{\circ} / 00\right.$ de salinidad y $6,6^{\circ} \mathrm{C}$ de temperatura a los 1.000 metros de profundidad).

Si los puntos que definen el origen y el final de la masa de agua se indican sobre un gráfico ST, cualquier valor de las variables salinidad y temperatura del núcleo de la capa, determinarán un punto que caerá sobre la recta que une ambos extremos que se han definido. Si además se considera que el punto inicial significa agua subantártica $100 \%$ y el final una mezcla donde el contenido subantártico original es menor de $1 \%$, los puntos intermedios indicarán mezclas cuyo contenido de agua subantárticas original será inversamente proporcional a su distancia del origen.

La curva que determinó Wüst es utilizable solamente para valores correspondientes al núcleo de las aguas subantárticas puesto que las aguas superficiales son considerablemente calentadas por la radiación solar dando puntos que se alejan de la curva construida como acabamos de ver. Por este motivo hemos calculado la recta de regresión entre temperatura y salinidad para aguas superficiales $(0$ a $100 \mathrm{~m})$ utilizando los datos de las campañas argentinas. La ecuación de la recta es $\mathbf{Y}=4,66+7,67 \mathbf{X}$; donde $\mathbf{X}=\mathrm{S}^{0} / 00,-34,00 ; \mathbf{Y}$ indica la temperatura en grados centígrados. El coeficiente de regresión es igual a 0,93 .

En la Figura 3, se han dibujado las rectas que indican la variación de la composición del núcleo (recta B) y en superficie, (recta A). La curva A ha sido terminada en un punto definido por $34,95 \%$ de salinidad y $12^{\circ} \mathrm{C}$ de temperatura, característica de 


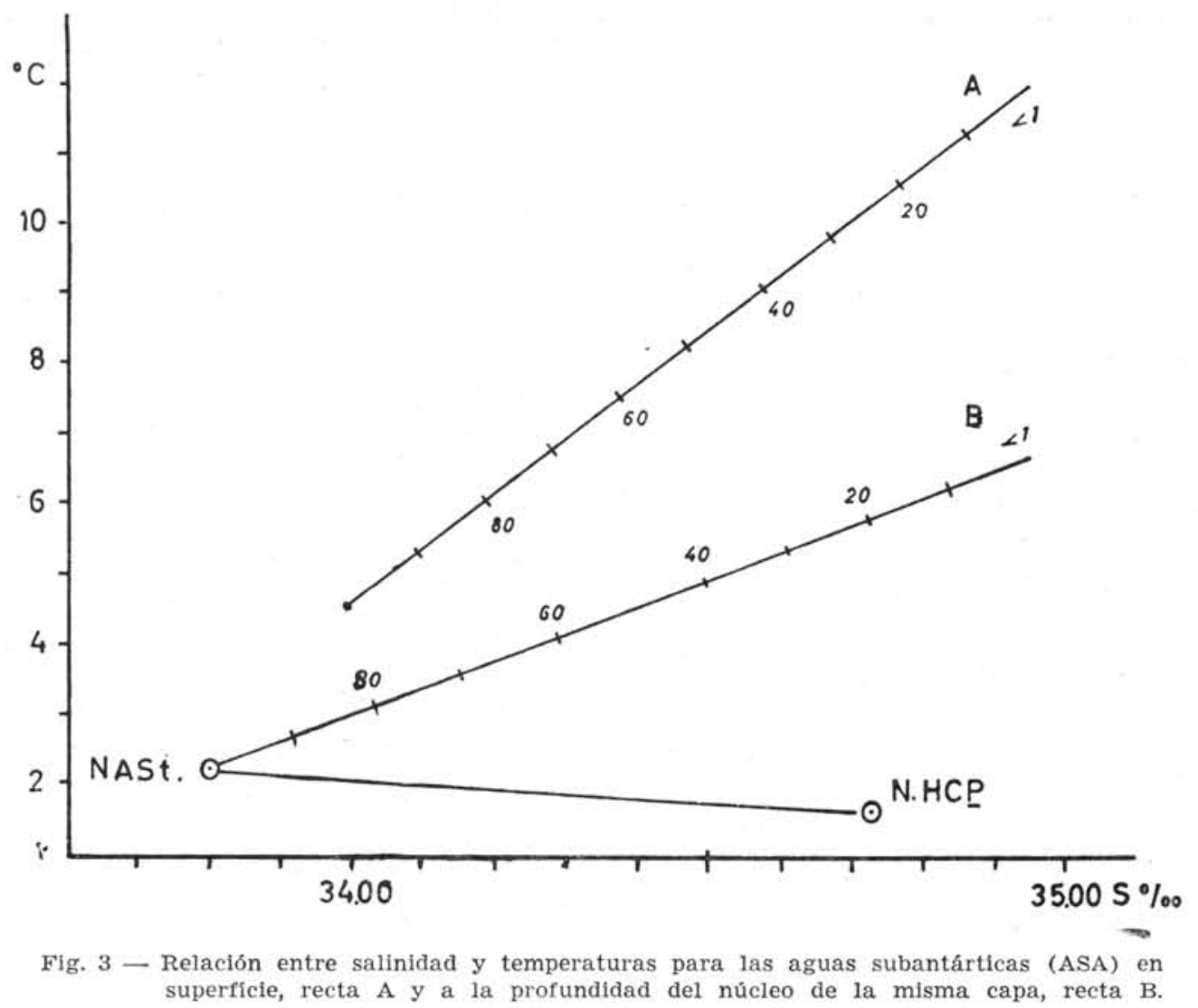

una mezcla en la cual la proporción de componente subantártico original es nula, (confrontar, LusQuiÑos, 1966). Para determinar las características de las aguas subantárticas puras en superficie hemos considerado los valores medios observados en el sector este de las Islas Malvinas (información, Campaña Malvinas, Station List Discovery Committee).

El sector aludido está situado entre $50^{\circ}$ a $53^{\circ} \mathrm{S}$ y $40^{\circ}$ y $45^{\circ} \mathrm{W}$. Las salinidades observadas oscilan entre $33,80^{\circ} \%$ y $34,09^{\circ} \%$, para verano e invierno y respectivamente.

Tomaremos por lo tanto como salinidad característica de las aguas subantárticas puras en superficie el valor medio de $33,99^{\circ} \%$.

La temperatura es la que corresponde de acuerdo con la recta de regresión, es decir $4,58^{\circ} \mathrm{C}$. La recta así limitada dividida en diez partes iguales nos permitirá calcular los porcentajes de agua subantártica original en una mezcla con agua subtropical en superficie.

\section{2 - Distribución de Oxígeno y Salinidad en la superficie}

En las Figuras 4 y 5 se observan las distribución de las isohalinas y las isolineas de oxígeno para la temporada invernal. En las Figuras 6 y 7 , las correspondientes a la primavera.

Teniendo en cuenta la distribución de las isohalinas podemos considerar cuatro zonas. La primera está limitada por las isohalinas de $34,00^{\circ} / 00$ y $34,10^{\circ} \%$, corresponde a las aguas de la corriente de Malvinas con aguas subantárticas practicamente puras; la segunda zona, limitada por las isohalinas de 34,10 y $34,40^{\circ} \%$ de salinidad, aguas de mezcla con predominancia de aguas subantárticas; la tercera área, queda limitada por las isohalinas de 34,40 y $35,00^{\circ} \%$, donde la mezcla es más rica en aguas de origen subtropical. Finalmente la zona con salinidades superiores a $35,00^{\circ} / 0$, es francamente subtropical.

Hacia el oeste se encuentran las aguas que bañan la plataforma continental argentina las que han recibido el nombre de "aguas viejas" o "aguas reciduales", estan caracterizadas por una salinidad por lo general menor de $34,00 \%$, constituyen un problema muy particular del cual no nos ocuparemos en este artículo.

El área limitada por las isohalinas de 34,00 y $34,10^{\circ} / 00$, muestran la corriente de Malvinas (la isohalina de $34,00^{\circ} \%$, no ha sido dibujada a fin de no confundir el gráfico, corre prácticamente paralela a la isobata de 100 brazas que indica el límite de la plataforma continental), la cual se estrecha tomando el aspecto de una cuña al norte de los $40^{\circ} \mathrm{S}$. En primavera, sin bien el área correspondiente a esta corriente es más ancha, toma también una forma similar. La corriente de Malvinas parece desaparecer alrededor de los $37^{\circ} \mathrm{S}$ hundiéndose por debajo de las aguas subtropicales (AST). No se observan mayores variaciones respecto al avance norte de esta 
corriente en las dos épocas analisadas, por lo menos dentro de la presición que permiten la secuencia de las estaciones oceanográficas.

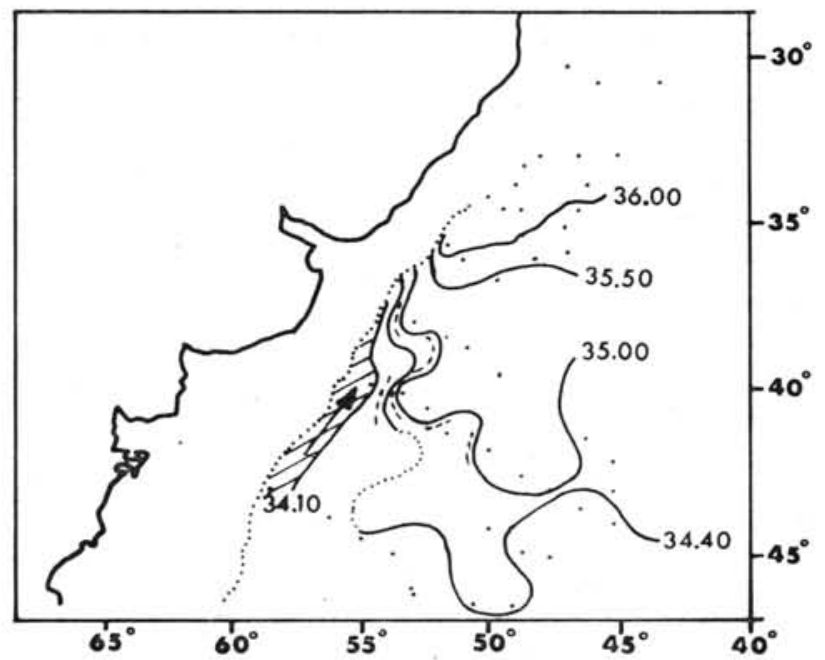

Fig. 4 - Distribución de las isohalinas en superficie durante el invierno.

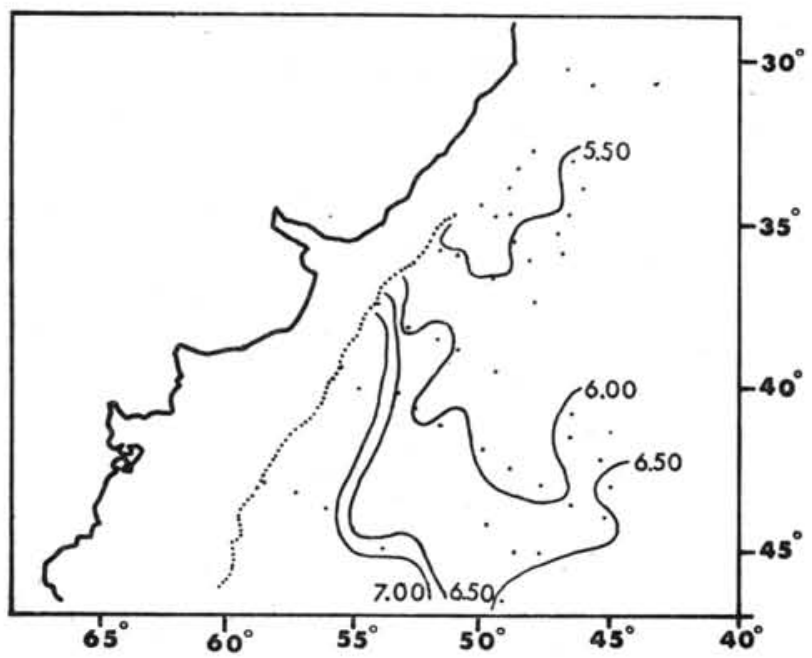

Fig. 5 - Distribución de oxigeno disuelto en superficie durante el invierno.

Hacia el Este y Norte de la corriente de Malvinas, especialmente al norte de $\operatorname{los} 40^{\circ} \mathrm{S}$, se presentan en invierno fuertes gradientes horizontales de salinidad. Análogo detalle se nota en primavera. Esto confirma la desaparición de la corriente de Malvinas y por lo tanto la presencia de la Convergencia Subtropical (C.St.). En las figuras se separan mediante punteado las estaciones oceanográficas entre las cuales se ha observado los máximos gradientes horizontales de salinidad. Estos deben coincidir con las zonas de hundimiento de las ASA y por lo tanto de la C.St. La importancia del proceso de hundimiento deberá ser proporcional al valor de esos gradientes. Por el contrario son de esperar gradientes horizontales mínimos de salinidad en un sentido coincidente con el flujo principal de la corriente.

Estos valores han sido hallados en la zona que se indica rayada en las figuras donde, además, una flecha indica la dirección y sentido del flujo.
La zona de mezcla entre las dos aguas que toman parte en el proceso convectivo, se extiende entre las isohalinas de 34,10 y $35,00^{\circ} / 00$.

Teniendo en cuenta la recta de regresión de la Figura 3, hemos dibujado la isohalina de $34,40^{\circ} / 0$ la cual indica las áreas de mayor o menor influencia de las A.S.A. según las salinidades sean menor ó mayor de $34,40 \%$, respectivamente. Comparando las Figuras 4 y 6 se observa que la posición de la C.St., asociada a la línea de puntos, tiene sus mayores fluctuaciones al Este de la corriente de Malvinas entre $\operatorname{los} 50^{\circ}$ y $55^{\circ} \mathrm{W}$, donde hay un avance de las A.S.T. hacia el sur, de alrededor de 200 millas náuticas con respecto a la situación en invierno. (En las estaciones correspondiente al invierno, TRIDENTE I, falta la $3 .^{\circ}$ pierna, lo cual impide precisar la posición de la isohalina de $35 \%$ pero, no obstante, los valores de salinidad superficiales correspondientes a las estaciones 457 e 459 , parecen indicar que el trazado dibujado no debe ser muy diferente del real).

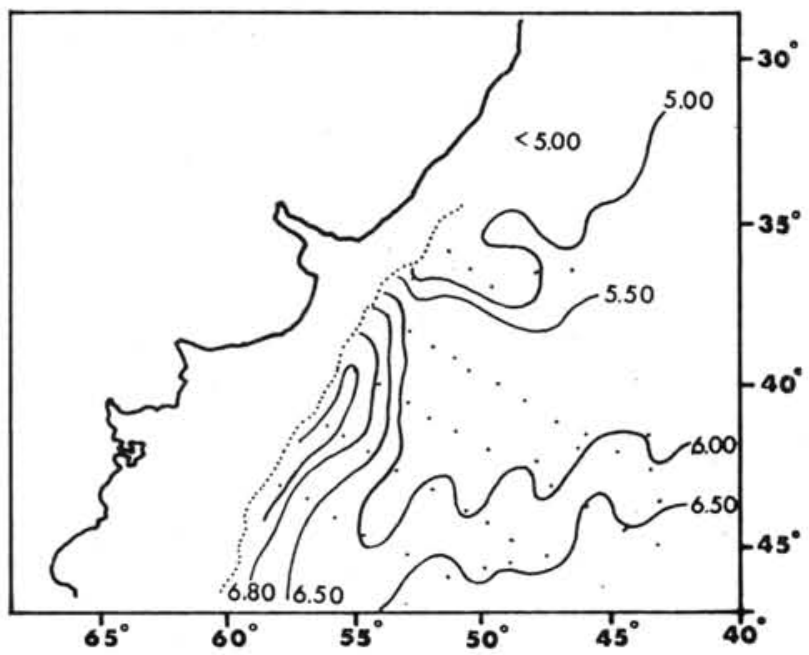

Fig. 6 - Distribución de las isohalinas en superficie durante la primavera.

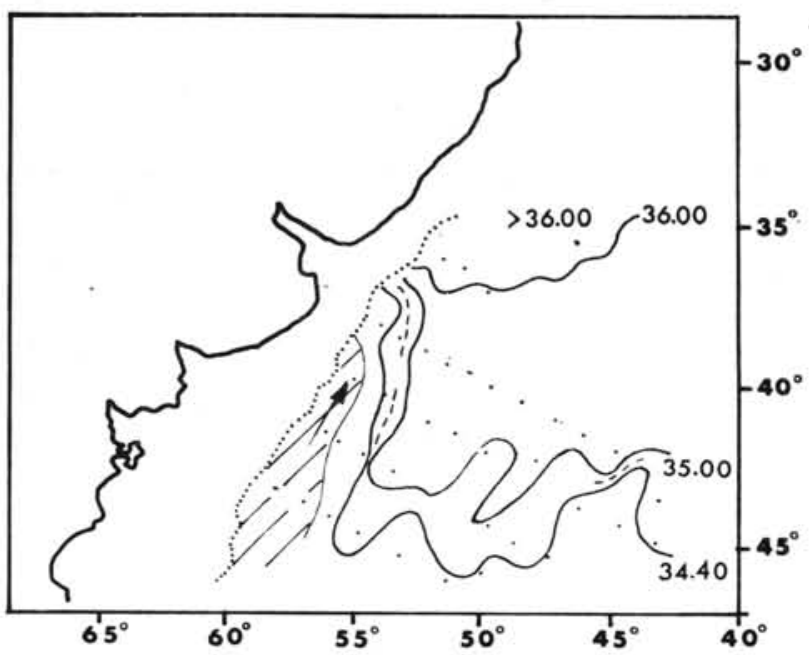

Fig. 7 - Distribución del oxigeno disuelto en superficie durante la primavera. 
En las Figuras 5 y 7 , se indica las distribución de isolineas de concentración de oxígeno $(\mathrm{ml} / \mathrm{l})$ en superficie para invierno y primavera respectivamente.
En las líneas generales la distribución de estas isolineas de oxígeno presentan una similitud con la distribución de isohalinas que acabamos de ver.

En la Figura 8, se ha dibujado un conjunto de
Rangos
oxigeno

$5,4-5,6 \mathrm{ml} / \mathrm{L}$

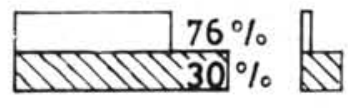

$3 \%$ $56 \%$

MII

$0 \%$

$\mathrm{S}>35,0 \%$ o $\quad 35,0-34,7 \%$ o $34,7-34,2 \%$ o $\quad S<34,2 \%$ 。

Rangos de Salinidad

$5,6-5,8 \cdots$

SIII)

$8 \% \square$
$16 \%$

$12 \%$

$87 \%$<smiles>[C+]1CCCC1</smiles>

$3 \%$

$0 \%$

$2,3 \%$ $0 \%$

$5,8-6,0$ "
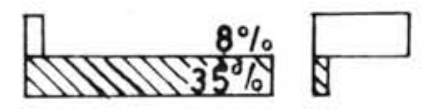

$34 \%$ $27 \%$

$2 \%$

$2 \%$

$6,0-6,2 \cdots$<smiles></smiles>

$4 \%$<smiles>C1CCC1</smiles>

$33 \%$

0

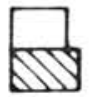

$11 \%$

$10 \%$

$0 \% \square$

$15 \%$

$0 \%$

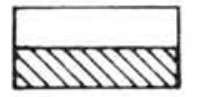

$31 \%$

$32 \%$

$2,3 \%$

$6,2-6,4 \cdot$

8

$4 \%$ -

$3 \%$

$5 \%$

$0 \%$

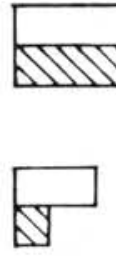

$36 \%$

$32 \%$

$23 \%$ $13 \%$

$6,6-6,8=$

\&

$0 \%$
$1 \%$

v

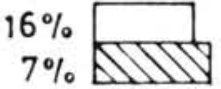

$27 \%$

$38 \%$

$6,8 \quad 7,0$

$0 \%$
$0 \%$

काजा

$32 \%$

$38 \%$

$7,0-7.2 ":$

$0 \%$

$0 \%$

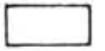

$23 \%$

$>7.2^{\prime \prime}$

Invierno

Primavera

?: 10 datos

Fig. 8 - Muestra la frecuencia en por ciento con que ciertos valores de oxigeno se distribuyen en cuatro rangos de salinidad. 
histogramas que representan la frecuencia con que los datos de oxígeno (muestras de 0 a 100 metros de profundidad), dentro de ciertos intervalos de concentración, se distribuyen entre cuatro rangos de salinidad. Se indica además, para cada rango de salinidad, cual es la distribución porcentual de los datos de concentración de oxígeno en los intervalos de concentración elegidos.

Analizando los mismos, se deduce que durante la temporada invernal las aguas con salinidades superiores a $35 \%$, están en el $81 \%$ de los casos asociados, concentraciones de oxígeno inferiores a $5,8 \mathrm{ml} / \mathrm{l}$. Solamente $9 \%$ de las muestras acusaron concentraciones de oxígeno superiores a $6 \mathrm{ml} / \mathrm{l}$.

Durante la primavera y para el mismo rango de salinidad, las concentraciones de oxígeno fueron inferiores a $6 \mathrm{ml} / 1$ en el $81 \%$; concentraciones superiores a aquel valor se observaron en el $16 \%$ de los casos. Teniendo en cuenta las dos épocas del año, las aguas con salinidad superior a $35 \%$ presentan, en un $85 \%$ de los casos concentraciones de oxígeno inferior a $6 \mathrm{ml} / \mathrm{l}$.

En las muestras de agua con salinidads menores de $34,20^{\circ} \%$, el contenido de oxígeno era, en el $90 \%$ de los casos, superior a $6,60 \mathrm{ml} / \mathrm{l}$; solamente $1 \%$ de los mismos mostraron concentraciones inferiores a $6,20 \mathrm{ml} 02 / 1$. Las aguas cuya salinidad estaba comprendida entre 34,20 y $34,70 \%$ oo tienen concentraciones de oxígeno superior a $6 \mathrm{ml} / 1$ en un $90 \%$ de los casos. De éstas el $78 \%$ estaba por arriba de $6,20 \mathrm{ml} 02 / 1$.

Teniendo en cuenta estas consideraciones, podemos aceptar que las aguas de superficie con concentraciones de oxígeno inferior a $6 \mathrm{ml} / \mathrm{l}$, son de marcada influencia subtropical. La influencia subantártica en cambio, está asociada a contenido de oxígeno superior a $6,50 \mathrm{ml} / \mathrm{l}$. Una característica de las aguas subantárticas, con un 80 a $90 \%$ de componente original, es la concentración de oxígeno superior a $6,80 \mathrm{ml} / \mathrm{l}$.

La máxima concentración de oxígeno la encontramos como es de esperar, en la zona de influencia de la corriente de Malvinas. Valores superiores a $7,00 \mathrm{ml} / 1$ de oxígeno son frecuentes en el invierno. El área limitada por la isolinea de $7 \mathrm{ml} / \mathrm{l}$, es superior a la que indicábamos para la corriente de Malvinas, por lo tanto son de esperar concentraciones de oxígeno superiores a $7 \mathrm{ml} / 1$ en el núcleo de la corriente.

También la distribución de oxígeno se observan fuertes gradientes horizontales de oxígeno en las mismas áreas donde habíamos situado la Convergencia Subtropical en base a la distribución de salinidad. La zona subtropical se caracteriza por concentraciones de oxígeno inferiores a $6 \mathrm{ml} / \mathrm{l}$; las salinidades superiores a $35,50 \%$, están por lo general asociados con valores inferiores a $5,50 \mathrm{ml} \mathrm{02/1}$.

En primavera, Figura 7 , también los máximos valores de la concentración de oxígeno en la superficie se situan en el área de influencia de la corriente de Malvinas. Los datos provenientes de la Campaña Tridente II (primavera) no muestran ningun valor de oxígeno superior a $6 \mathrm{ml} / \mathrm{l}$, en cambio se han informado concentraciones de este órden y superior durante la Campaña Productividad sobre áreas de plataforma continental argentina fuertemente influenciada por la corriente de Malvinas (SAYED, 1964). Estos valores muy altos deben estár muy problablemente asociados a una intensa actividad biológica, como indican los datos de asimilación de carbono a través de la fotósintesis de los organismos fitoplanctónicos.

En general podemos considerar como concentraciones medias para las aguas de la corriente de Malvinas en este época del año, 6,80 a $7,00 \mathrm{ml}$ de $02 / 1$.

En las dos épocas podemos anotar que en la zona de mezcla de aguas subantárticas y subtropicales las concentraciones de oxígeno varian entre 6 y $6,5 \mathrm{ml} / 1$ de oxígeno. El valor de $6,30 \mathrm{ml} / 1$ lo tomamos con el mismo significado que la salinidad de $34,40 \%$, es decir, una mezcla donde el aporte de los dos tipos de aguas son iguales. La isolinea de $6,30 \mathrm{ml} 02 / \mathrm{l}$, no ha sido dibujada para no confundir el dibujo, se la puede imaginar a una distancia intermedia entre las isolineas de 6 y $6,5 \mathrm{ml} / \mathrm{l}$.

Tanto la distribución de oxígeno como la de salinidad dan una información similar sobre la posición de la Convergencia Subtropical y la posición de la corriente de Malvinas y su máximo avance hacia el norte. Los parámetros que definen una masa de agua son temperatura y salinidad y dado que la solubilidad del oxígeno es una función de esas mismas variables, es de esperar que los gradientes de salinidad que indican la convergencia, estean tambien reflejados en la concentración de oxígeno. Esto explica los gradientes (negativos) horizontales de oxígeno en el área donde tiene lugar la Convergen. cia Subtropical.

\section{3 - La Saturación de Oxígeno}

La capa de agua superficial está regularmente saturada respecto al oxígeno, teniendo en cuenta los valores de solubilidad dados por Truesdale et al. (1955). Las sobresaturaciones de oxígeno también son frecuentes. El estrato saturado oscila entre 30 y 50 metros de profundidad (Tab. III y IV).

La saturación de oxígeno en las aguas superficiales es un fenómeno normal, cuando éstas han estado suficiente tiempo en contacto con la atmósfera. Si el sistema está en equilibrio la tensión de vapor de los gases de la atmósfera debe ser la misma en las dos faces del sistema aire-mar. Si el sistema no está en equilibrio, evolucionará hasta alcanzarlo, mediante el pasaje del gas de una fase a la otra. En épocas de una intensa actividad fitoplanctónica es posible encontrar un estrato superficial sobresaturado.

Este fenómeno puede producirse también como resultado de una mezcla de dos masas de agua exactamente saturadas de oxígeno, pero a temperaturas diferentes. En cambio se encuentran aguas superficiales no-saturadas de oxígeno $(50-60 \%$ de saturación o menos), en zonas donde se produzcan afloramientos de aguas profundas, las que nunca es- 
TABLA III - Profundidad de la termoclina y de la capa sobresaturada de oxígeno en estaciones de invierno

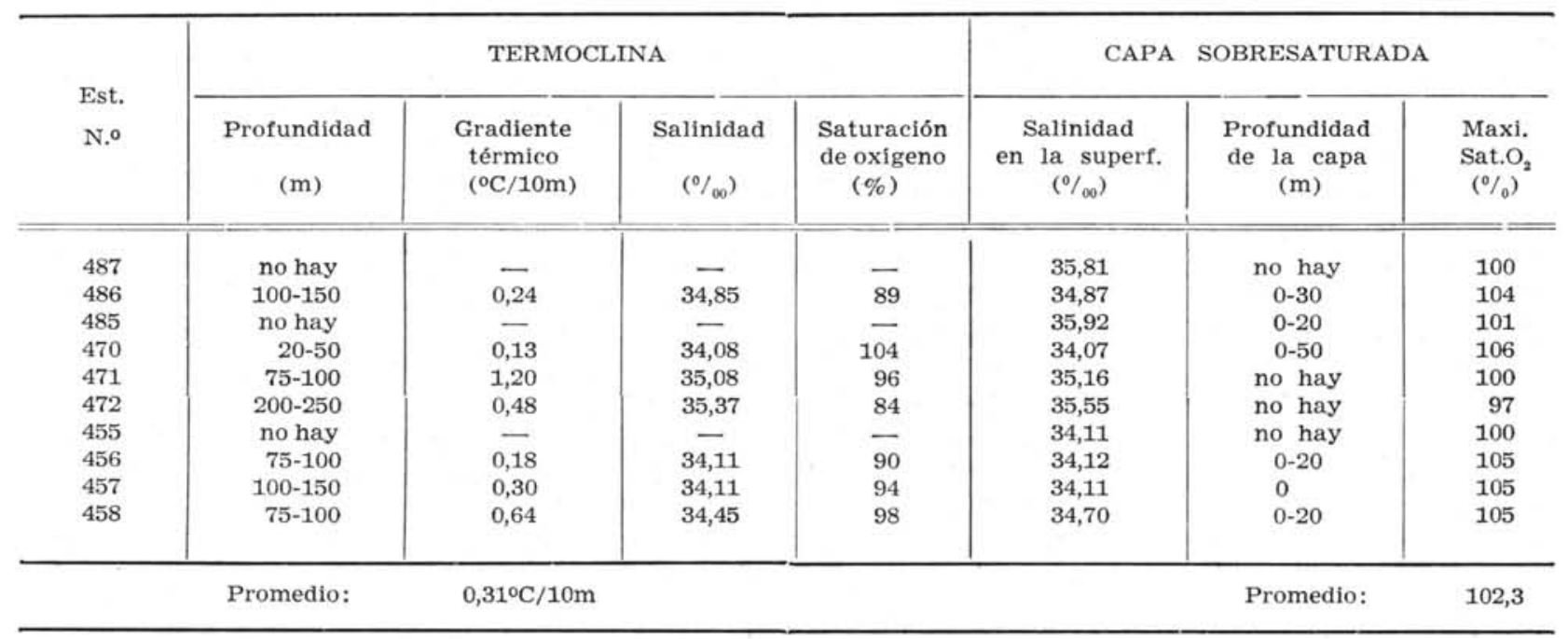

TABLA IV - Profundidad de la termoclina y de la capa sobresaturada de oxigeno en estaciones de primavera

\begin{tabular}{|c|c|c|c|c|c|c|c|}
\hline \multirow{2}{*}{$\begin{array}{l}\text { Est. } \\
\text { N.o }\end{array}$} & \multicolumn{4}{|c|}{ TERMOCLINA } & \multicolumn{3}{|c|}{ CAPA SOBRESATURADA } \\
\hline & $\begin{array}{l}\text { Profundidad } \\
\text { (m) }\end{array}$ & $\begin{array}{l}\text { Gradiente } \\
\text { térmico } \\
\left({ }^{\circ} \mathrm{C} / 10 \mathrm{~m}\right)\end{array}$ & $\begin{array}{l}\text { Salinidad } \\
\qquad(\%)\end{array}$ & $\begin{array}{c}\text { Saturación } \\
\text { de } \\
\text { oxigeno } \\
(\%)\end{array}$ & $\begin{array}{c}\text { Salinidad } \\
\text { en la } \\
\text { superf. } \\
(\%) \\
\end{array}$ & $\begin{array}{c}\text { Profundidad } \\
\text { de la } \\
\text { capa } \\
\text { (m) } \\
\end{array}$ & $\begin{array}{l}\text { Máxim. } \\
\text { Sat. } 0_{2} \\
(\%)\end{array}$ \\
\hline 495 & $50-75$ & 0,44 & 35,69 & 91 & 34,54 & $0-30$ & 108 \\
\hline 496 & $50-57$ & 0,63 & 35,69 & 101 & 35,21 & $0-50$ & 110 \\
\hline 497 & $20-30$ & 0,51 & 35,45 & 108 & 35,29 & $0-30$ & 109 \\
\hline 498 & $50-100$ & 0,57 & 35,40 & 103 & 35,39 & $0-100$ & 108 \\
\hline 514 & $10-20$ & 0,18 & 35,70 & 110 & 35,39 & $0-50$ & 110 \\
\hline 513 & $50-75$ & 0,23 & 35,56 & 99 & 35,71 & no hay & 101 \\
\hline 515 & $100-150$ & 0,20 & 35,62 & 90 & 35,61 & no hay & 98 \\
\hline 516 & $20-30$ & 1,00 & 34,10 & 106 & 34,52 & $0-30$ & 107 \\
\hline 520 & $30-75$ & 0,77 & 34,14 & 106 & 34,09 & $0-75$ & 111 \\
\hline 526 & $0-150$ & 0,30 & 34,05 & 102 & 34,13 & $0-100$ & 110 \\
\hline 527 & $30-50$ & 1,76 & 34,12 & 107 & 33,98 & $0-50$ & 111 \\
\hline 528 & $0-30$ & 1,00 & 34,09 & 105 & 34,12 & $0-30$ & 107 \\
\hline 529 & $50-75$ & 1,17 & 34,35 & 80 & 34,09 & no hay & 95 \\
\hline 530 & $20-30$ & 1,26 & 34,06 & 108 & 34,35 & $0-30$ & 110 \\
\hline 540 & $20-50$ & 1,07 & 34,13 & 115 & 34,06 & $0-100$ & 117 \\
\hline 541 & $20-50$ & 1,57 & 34,14 & 117 & 34,13 & $0-50$ & 121 \\
\hline \multicolumn{2}{|r|}{ Promedio: } & $0,79^{\circ} \mathrm{C} / 10 \mathrm{~m}$ & & & & Promedio: & $110 \%$ \\
\hline
\end{tabular}

tán saturadas por el consumo de oxígeno que ha tenido lugar en su seno.

En ninguna oportunidad hemos encontrado aguas superficiales no-saturadas en el área de estudio, lo cual hace díficil sostener la hipótesis de presencia de afloramientos ("up-welling") en el área de influencia de la corriente de Malvinas como ha sostenido CAPURRo (1955).

La sobre-saturación está asociada con fuertes termoclinas, como puede observarse en las Tablas III y IV. Este detalle podría permitir sustentar la hipótesis de un origen físico de la sobresaturación. Este se produciría por un recalentamiento brusco de la napa superficial, de modo que ésta normalmente saturada, quedaría con una concentración de oxígeno superior al que corresponde al equilibrio, al aumentar la temperatura del agua superficial. La gran actividad de las algas fitoplanctónicas por una parte y el bajo coeficiente de difusión del oxígeno por la otra, contribuyen a que el estado de desequilibrio se mantenga. Durante la primavera, el gradiente medio en la termoclina es de $1,09^{\circ} \mathrm{C} / 10$ metros, en invierno en cambio fué solamente de $0,37^{\circ} \mathrm{C} / 10$ metros. El porcentaje medio de saturación de oxígeno fué de $110 \%$ y $103 \%$ en primavera e invierno respectivamente. 


\section{4 - Distribución de Oxígeno y Salinidad en las Capas Subsuperficiales}

\section{a) Oxígeno al nivel de 100 metros}

En las Figuras 9 y 10 se han dibujado las lí. neas de igual concentración de oxígeno disuelto, para invierno y primavera respectivamente.

Las concentraciones de oxígeno a este nivel no muestra mayores diferencias entre las dos épocas del año $\mathrm{y}$, en líneas generales, refleja las condiciones observadas en superficie. Las concentraciones máximas se encuentran sobre el borde oeste, pegadas al borde del talud continental. Al norte de los $36^{\circ} \mathrm{S}$, las concentraciones disminuyen a valores menores de $5 \mathrm{ml} \mathrm{02/1}$.

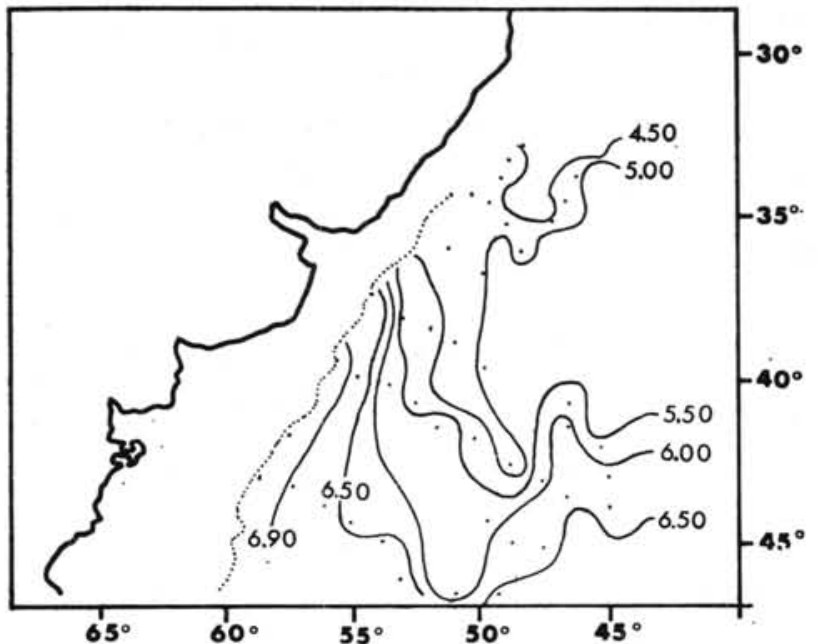

Fig. 9 - Distribución de oxígeno al nivel de 100 metros durante el invierno.

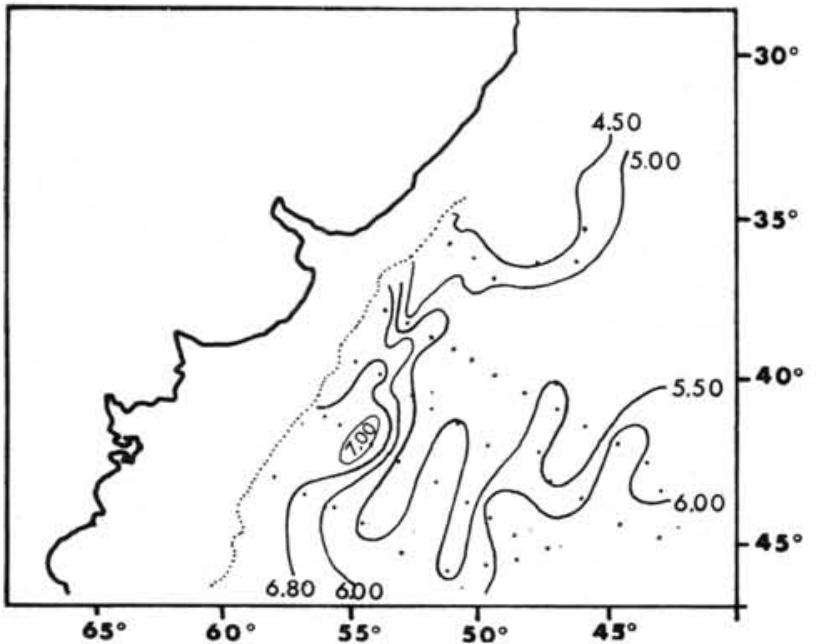

Fig. 10 - Distribución le oxigeno al nivel de 100 metros durante la primavera.

La posición de la isolinea de $5 \mathrm{ml} / 1$ se presenta mucho más al sur en invierno que en primavera. La posición dibujada está apoyada por la presencia de concentraciones menores de $5 \mathrm{ml} 02 / 1$ en las Estaciones 485 y 475 . Las concentraciones máximas alrededor de $6,90 \mathrm{ml} 02 / 1$, están cercanas al talud continental al sud de los $40^{\circ} \mathrm{S}$.

En ambas épocas del año se nota un avance hacia el sud de las isolineas de $5,5 \mathrm{ml} 02 / 1$, entre $48^{\circ}$ y $53^{\circ} \mathrm{W}$. Este hecho es especialmente notable en la primavera, cuando la inclusión de agua menos oxigenada llega hasta casi $46^{\circ} \mathrm{S}$. De este hecho resulta que los gradientes de oxígeno hacia el Este de la corriente de Malvinas son más fuertes que en invierno, dando la impresión de que las aguas subantárticas fueran "comprimidas" contra el talud continental. De ello se puede deducir que el fenómeno de hundimiento tiene lugar con mayor intensidad que en el invierno.

Las aguas subantárticas de la corriente de Malvinas, no avanzan más al norte de los $37^{\circ} \mathrm{S}$, como vimos en superficie, esto se desprende de los fuertes gradientes negativos de oxígeno que se observan sobre el borde del talud a esa latitud.

\section{b) Salinidad y Oxígeno al nivel de 200 metros}

En las Figuras 11 y 12 se han dibujado las isohalinas a 200 metros de profundidad correspondiente al invierno y primavera respectivamente.

$\mathrm{Al}$ sud de los $39^{\circ} .40^{\circ} \mathrm{S}$, las condiciones son muy similares a las vistas en superficie, es decir, la mínima salinidad se situa sobre el talud continental. Este detalle es observable en las dos estaciones del año. La diferencia más notable respecto a la distribución de isohalinas en superficie, es la aparición de una lengua de agua de baja salinidad que se introduce profundamente hacia el NE, a partir de la Estación 486. El trazado de la isohalina de $35^{\circ} \%$, tal como fué realizado, está apoyado en la presencia de aguas de salinidad $34,90^{\circ} \%$ y $35,12^{\circ} / 00$, en las estaciones 757 y 756 de la Campaña Tridente Brasileña. Además en esta última estación se encontró $34,49^{\circ}$ oo de salinidad a 385 metros. En la estación 751 TB, a 350 metros la salinidad fué de $34,29^{\circ} \%$.

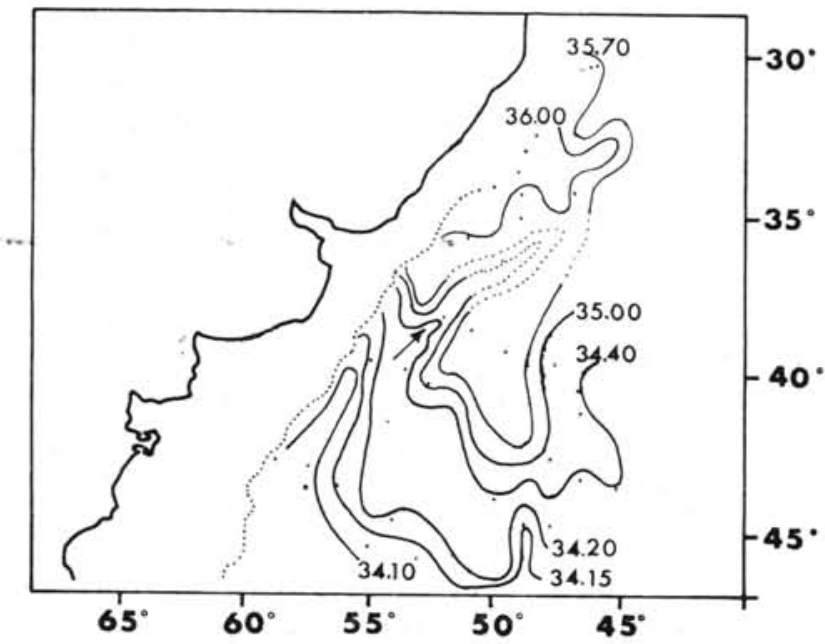

Fig. 11 - Isohalinas al nivel de 200 metros durante el invierno. 


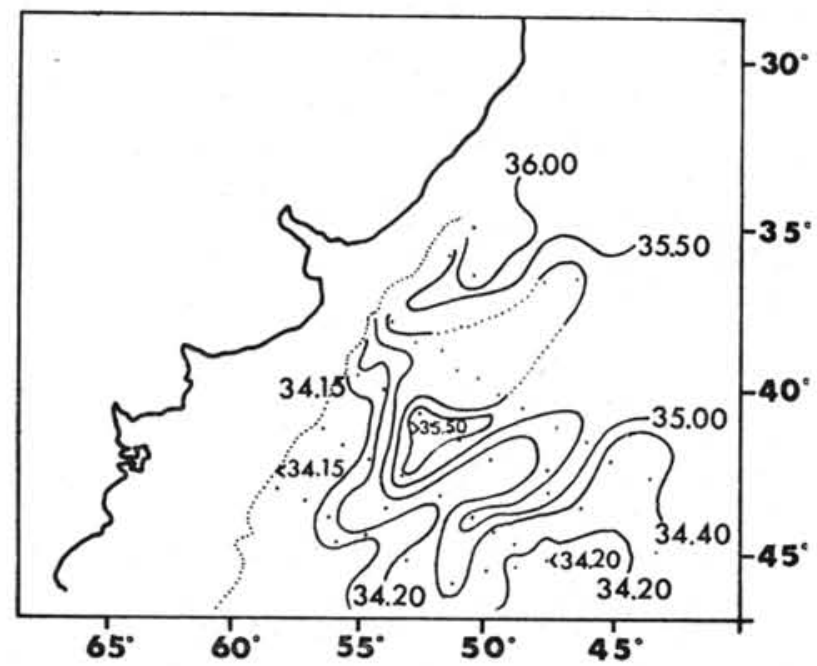

Fig. 12 - Isohalinas al nivel de 200 metros durante la primavera.

Este detalhe es el primer indicio de la dirección de la deriva norte de las aguas subantárticas una vez que han dejado la superficie. Este hecho se acentúa notablemente a más profundidad.

En las estaciones 384 y 385 del primer perfil (Campaña Tridente Argentina) se encontraron salinidades muy superiores a las vistas en superficie. En la última de éstas, la salinidad a 200 metros fué superior a $35,80^{\circ} \%$. Estas estaciones citadas así también como las 472,474, y 475 , presentan características típicas de aguas subtropicales. Todo esto indica, como ya vimos más arriba, que el avance hacia el sur de las aguas de la corriente de Brasil, tiene lugar a cierta distancia del borde del talud, unas 240 millas al este, a latitudes superiores a $37^{\circ} \mathrm{S}$. La posición de la isohalina de $35^{\circ} \%$ de salinidad al sud de $\operatorname{los} 40^{\circ} \mathrm{S}$, es idéntica a la observada en superficie.

En ambas figuras se indica con una flecha, la dirección y sentido en la cual los gradientes de salinidad son mínimos, es decir, coincidiendo con la dirección del flujo de la deriva del ASA.

Durante la primavera la distribución de isohalinas presenta en líneas generales una distribución similar a la de invierno. Es de hacer notar que el ancho de la cuña de ASA en dirección NE, es considerablemente más ancha que en invierno. Este trazado está apoyado en el hecho de que no se ha observado ninguna salinidad superior a $35^{\circ} \%$ en las nueve estaciones del primer perfil de la Campaña Tridente II (Cap. Cánepa). Además las salinidades en las estaciones 821 y 822 , de la Campaña Tridente II (Brasil), acusan a 200 metros de salinidades de 34,35 y $34,90^{\circ} \%$ respectivamente.

En las dos estaciones del año se observan a este nivel, zonas de fuertes gradientes horizontales de sa. linidad, lo cual es índice que el proceso de hundimiento de las ASA, continúa a este nivel con cierta intensidad.

En las Figuras 13 y 14, se han dibujado las líneas de igual concentración de oxígeno a $200 \mathrm{me}$ tros de profundidad, para invierno y primavera, respectivamente.

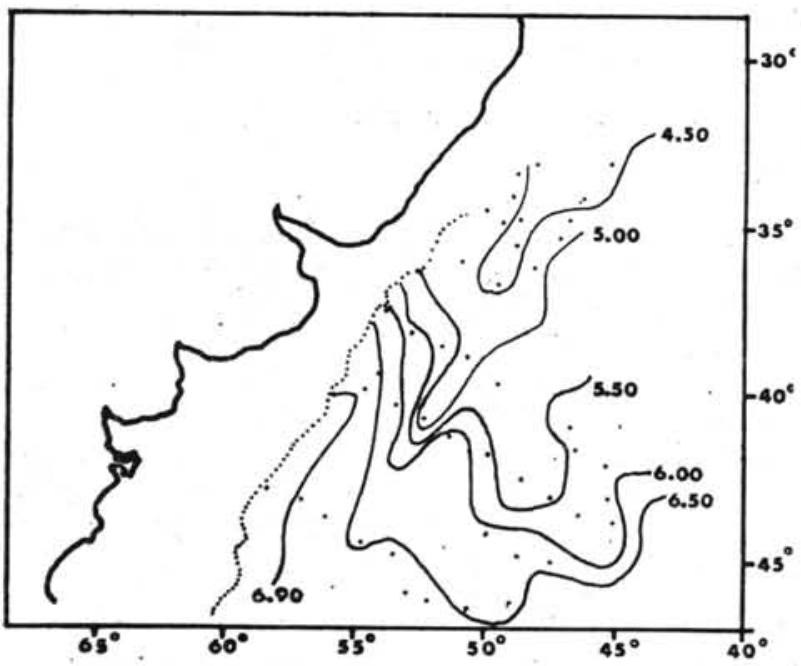

Fig. 13 - Distribución de oxigeno al nivel de 200 metros durante el invierno.

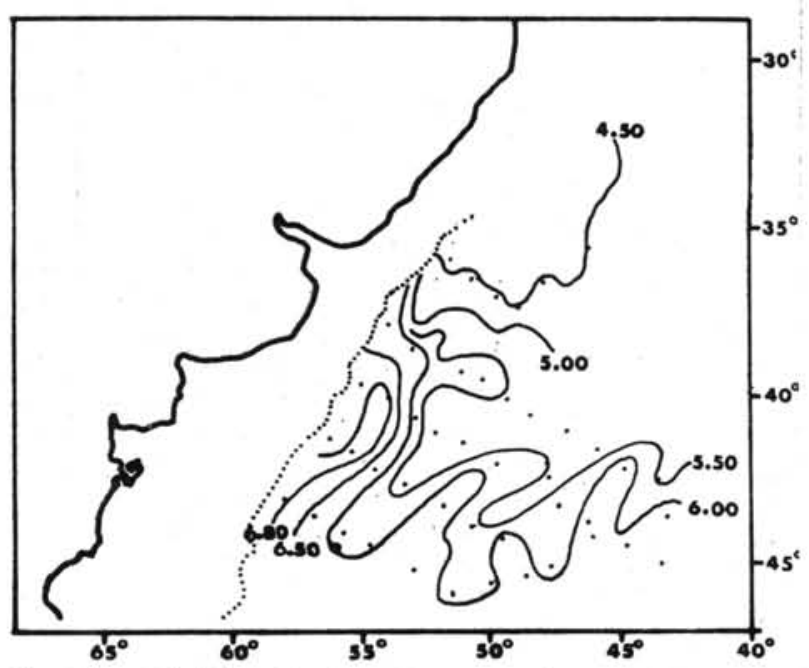

Fig. 14 - Distribución de oxigeno al nivel de 200 metros durante la primavera.

Analizando la distribución de esta variable, observamos que concuerda con las apreciaciones hechas teniendo en cuenta la distribución de la salinidad.

Como en los otros niveles ya vistos, la máxima concentración de oxígeno que presenta sobre el borde del talud continental coincidiendo con el área de las mínimas salinidades. Las concentraciones de oxígeno son altas en ambas épocas, alderedor de 6,80 $\mathrm{ml} 0,2 /$. Se nota una leve superioridad en las concentraciones de oxígeno invernales.

La distribución de oxígeno en relación con la zona de influencia de las dos masas de agua, presenta buena coincidencia con las observaciones en base a la distribución de salinidad. La existencia de la amplia lengua de ASA que observamos se introduce al norte de $40^{\circ} \mathrm{S}$ con dirección $\mathrm{NE}$, está también justificada en base al contenido de oxígeno en las estaciones del primer perfil de las campañas argentinas, donde se anotan concentraciones de oxígeno entre 5,50 y $6,00 \mathrm{ml} / \mathrm{l}$, que corresponden a salinidades inferiores a $35 \%$. En cambio la baja 
salinidad de las estaciones brasileñas no está reflejada para nada en el contenido de oxígeno. Por el contrario, presenta concentraciones características de aguas de salinidades de alrededor de $35,80^{\circ} \%$ o. Por este motivo en las figuras que muestran la distribución de las isohalinas al nivel de 200 metros, se indica con un punteado, queriendo significar que esa es la dirección del flujo de ASA, pero que a esta profundidad aún no está suficientemente bien definida.

La isolinea de $6,00 \mathrm{ml} 02 / \mathrm{l}$, tiene un cierto paralelismo con la isohalina de $34,40^{\circ} \%$, por ese motivo asociamos esa concentración de oxígeno con mezcla en la cual el aporte de cada uno de los componentes es del $50 \%$. Las concentraciones superiores a $6 \mathrm{ml} / \mathrm{l}$ de oxígeno están ahora asociadas a una mayor influencia de aguas subantárticas. Comparando las Figuras 11 y 13, vemos que la isohalina de $34,20 \%$, que indica una mezcla en la cual la contribución del ASA es del $70 \%$ (Graf. 3, recta B), tiene una disposición similar a la línea que indica la concentración de $6,50 \mathrm{ml} / 1$ de oxígeno.

Las máximas concentraciones de oxígeno las observamos en zonas donde la salinidad es alrededor de $34,10 \%$, lo cual significa ASA, con una proporción de componente original de 75 a $80 \%$. Esta es la máxima concentración de componentes subantártico a estas latitudes de 40 a $45^{\circ} \mathrm{S}$.

Los fuertes gradientes horizontales de salinidad también tienen su reflejo en los gradientes de oxígeno, con el mismo significado ya visto.

\section{c) Oxígeno al nivel de 400 metros}

En las Figuras 15 y 16 se han trazado las lí. neas que unen los puntos de igual concentración de oxígeno al nivel de 400 metros de profundidad, para invierno y primavera respectivamente.

En la figura correspondiente a la distribución de oxígeno invernal observamos que aún se sigue presentando el máximo de oxígeno en la zona oeste. sobre el talud continental, solamente que el área ahora es menor que a los niveles superiores. La máxima concentración de oxígeno es de $6,50 \mathrm{ml} / \mathrm{l}$, en los niveles más profundos correspondientes a la temporada invernal, encontraremos concentraciones de oxígeno siempre inferiores, lo cual indica que ya estamos a esta profundidad por debajo del máximo oxígeno. En la figura que corresponde a la primavera, encontramos aún concentraciones de oxígeno superiores a $6,50 \mathrm{ml} / \mathrm{l}$, pero alejadas del talud continental, es decir, el área de máximo oxígeno que se situaba pegada al talud ha desaparecido a esta profundidad.

Otro aspecto de interese que presenta la distribución de oxígeno en primavera es que la zona cercana al talud tiene concentraciones de oxígeno inferiores a $6 \mathrm{ml} / \mathrm{l}$, pero lo que es interesante hacer notar es que éstas aguas están asociadas a temperaturas de $3^{\circ} \mathrm{C}$ (Est. 526 ), $2,6^{\circ} \mathrm{C}$ (Est. 246) y $2,86^{\circ} \mathrm{C}$ (Est. 542). Las salinidades que le corresponden son respectivamente de 34,$18 ; 34,24$ y $34,22^{\circ} \%$. Estos detalles nos indican que la disminución de concen-

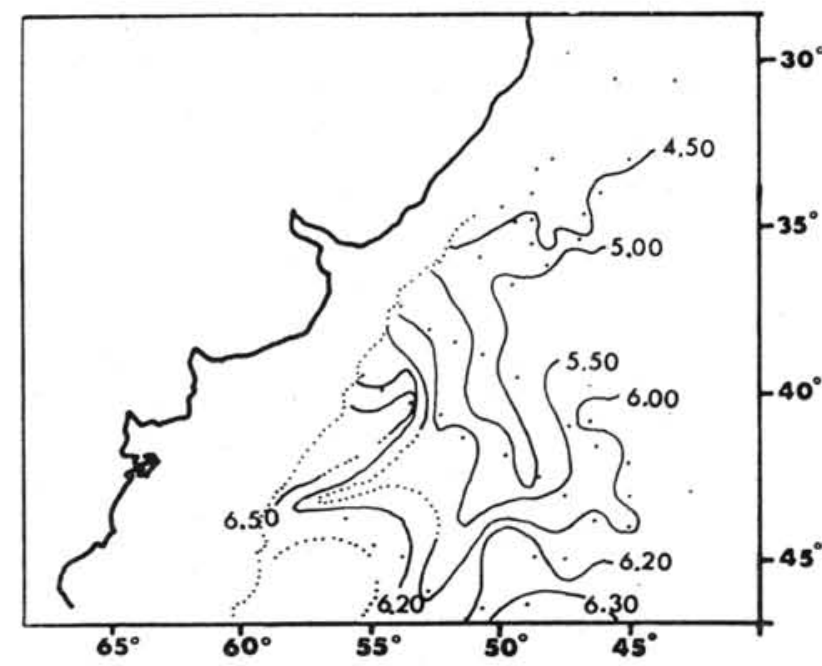

Fig. 15 - Distribución de oxigeno al nivel de 400 metros durante el invierno.

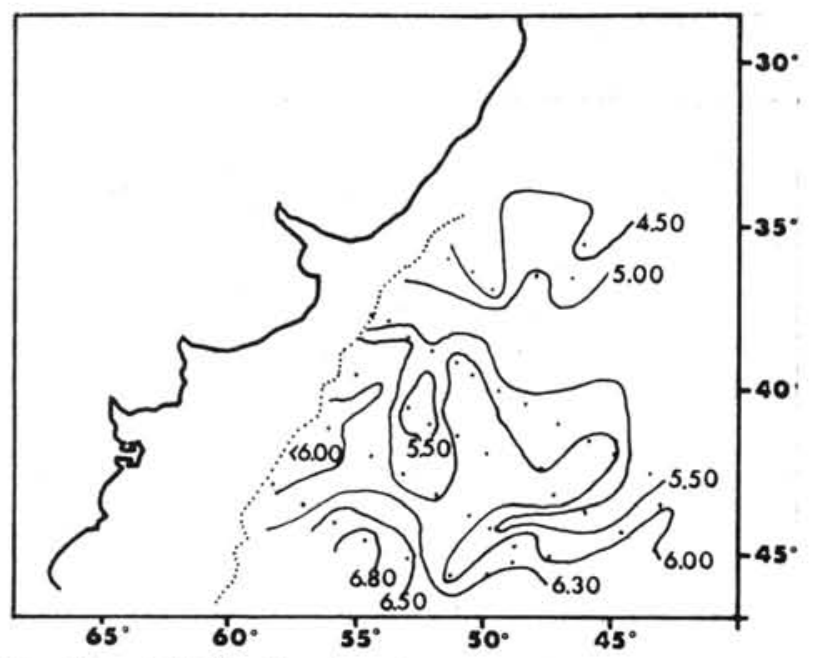

Fig. 16 - Distribución de oxigeno al nivel de 400 metros durante la primavera.

tración de oxígeno es debida, en esta área, a la influencia de la masa de Agua Cálida Profunda (ACP) que se situa por debajo del ASA.

En las estaciones 514 y 516, también correspondiente al perfil primaveral, se observa un bolsón con concentraciones de oxígeno inferiores a $5,50 \mathrm{ml} / \mathrm{l}$. Pero estos puntos están asociados a temperatura y salinidad superiores respecto a las cercanas al talud. Tenemos $13,19^{\circ} \mathrm{C}$; y $35,64^{\circ} \%$ oo de salinidad en la estación 514; en la 515, la temperatura es de $8,22^{\circ} \mathrm{C}$ y $34,57^{\circ} \%$ oo de salinidad.

Los valores de la estación 514 corresponden indudablemente a aguas subtropicales; en la segunda, la influencia es menor.

\section{d) Salinidad y Oxígeno al nivel de 600 metros}

Las Figuras 17 y 18 representan las isohalinas al nivel de 600 metros de profundidad, en invierno y primavera respectivamente. 
En invierno observamos que practicamente toda el área está ocupada por aguas de salinidad menor de $34,30^{\circ} \% 0$. La isohalina de $34,80^{\circ} \%$, recién se la observa a los $35^{\circ} \mathrm{S}$ sobre el talud brasileño. Las salinidades mínimas se encuentran en las estaciones 757 y 756 (Tridente Brasil) con valores de alrededor de $34,10^{\circ} \%$.

Un valor similar se encuentra en la estación 477 (Tridente Argentina), pero a unas 400 millas al SSE de las estaciones brasileñas.

Al ocuparnos de la distribución de salinidad al nivel de 200 metros de profundidad, habíamos hecho notar la existencia de agua de baja salinidad en las estaciones brasileñas arriba mencionadas. Es indudable que no puede tener otro origen que el subantártico, solamente llama la atención el valor tan bajo de la salinidad a latitudes donde el núcleo de agua intermedia debería tener valores algo superiores al observado. Esto es especialmente notable si tenemos en cuenta que en las estaciones del primer perfil de la Campaña Tridente I (Argentina) los valores sa salinidad para el núcleo de las aguas

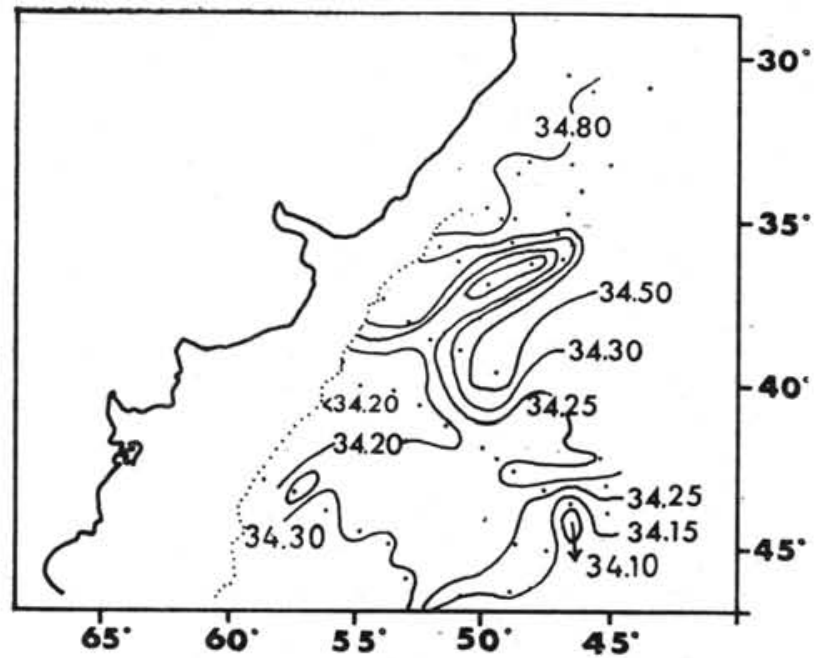

Fig. 17 - Isohalinas al nivel de 600 metros durante el invierno.

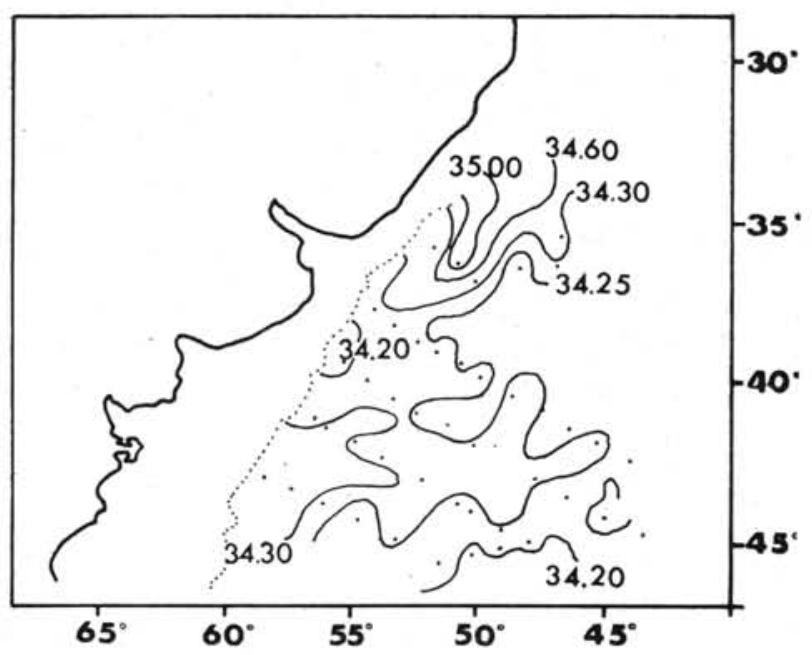

Fig. 18 - Isohalinas al nivel de 600 metros durante la primavera. intermedias es algo superior. En las estaciones brasileñas, 758, 759, 733, y 755, las salinidades confirman la presencía de aguas intermedias (subantárticas), aunque con valores que estimamos demasiado bajos para esa latitudes. Los datos recogidos por el Atlantis, estaciones 5808 ( $32^{\circ} 33^{\prime} \mathrm{S}$; $49^{\circ} 32^{\prime} \mathrm{W}$ ) y 5809 (32 $\left.29^{\prime} \mathrm{S}-44^{\circ} 42^{\prime} \mathrm{W}\right)$ (FLUGISTER, op. cit.) indican valores minimos de salinidad de $34,303^{\circ} \%$ a 980 $\mathrm{m} ;$ y $34,235 \%$ a $950 \mathrm{~m}$ respectivamente. Si bien las posiciones son algo más al norte que la de las estaciones brasileñas, los valores de salinidad y la profundidad están más de acuerdo con las condiciones que observamos al nivel de 1000 metros (Fig. 23) en el área brasileña.

La salinidad observada en la estación 477 TC, corresponden al núcleo del agua subantártica y este valor de $34,10^{\circ} \%$ de salinidad, está de acuerdo con la latitud y con el contenido de oxígeno, como veremos en seguida.

A esta profundidad de 600 metros, durante el invierno observamos que la mayor parte del área central cubierta por la Campaña Tridente I (Argentina), está ocupada por el núcleo del agua subantártica. La isohalina de $34,20^{\circ} \%$, limita dos áreas donde la salinidad es menor de este valor. Una de ellas hacia el oeste y la otra hacia el sudeste. La primera está asociada a temperaturas y concentraciones de oxígeno bajas, lo cual indica, como ya dijimos al referirnos al nivel anterior, influencia de las ACP. La otra en cambio, las bajas salinidades se corresponden con las mayores concentraciones de oxígeno, es decir, agua subantártica con el máximo contenido de componente original. $\mathrm{Al}$ sud del área estudiada, sobre el último perfil, se situa la isohalina de $34,30^{\circ} /{ }_{00}$, hacia el sud las salinidades parecen aumentar. El núcleo del agua subantártica se encuentra por arriba de 600 metros y la influencia del agua CP se comienza a hacer sentir.

Observando la distribución de oxígeno durante esta misma época (Fig. 19), notamos un buen índice de la influencia de las distintas masas de agua. Los máximos de oxígeno cercanos a $6,30 \mathrm{ml} / \mathrm{l}$ de oxígeno, se encuentran en la zona central y sudeste, donde ubicamos la mayor influencia de aguas sub. antárticas. Las bajas salinidades sobre el costado oeste coinciden con bajos valores de oxígeno.

Hacia el norte la isohalina de $34,25 \%$, mantiene un buen paralelismo con la línea de $5,00 \mathrm{ml} / 1$ de oxígeno. A esa salinidad asociamos una concentración de componente original superior a $60 \%$, o sea, que concentraciones de oxígeno superiores a $5,00 \mathrm{ml} / \mathrm{l}$, nos indican aguas con un porcentaje de influencia subantártica aún mayor.

Las mínimas salinidades situadas de los $36^{\circ} \mathrm{S}$, no están reflejadas en las concentraciones de oxígeno que podrían esperarse de acuerdo con esos valores de salinidad. Un detalle similar se observa en la estación $477 \mathrm{TC}$, donde también se encontró una salinidad de $34,10^{\circ} \%$. En este último caso, es problable de que se trate de las aguas subantárticas inferiores, que de acuerdo con DEAcon (1933, p. 206) son más antárticas en su origen. La temperatura, relativamente haja, $3,1^{\circ} \mathrm{C}$, podría indicar aguas de superficie antártica hundida durante el verano con 
una concentración de oxígeno alto que explica su concentración relativamente elevada para aguas que dejaron la superficie después de bastante tiempo (Menéndez \& Pizarro, 1965).

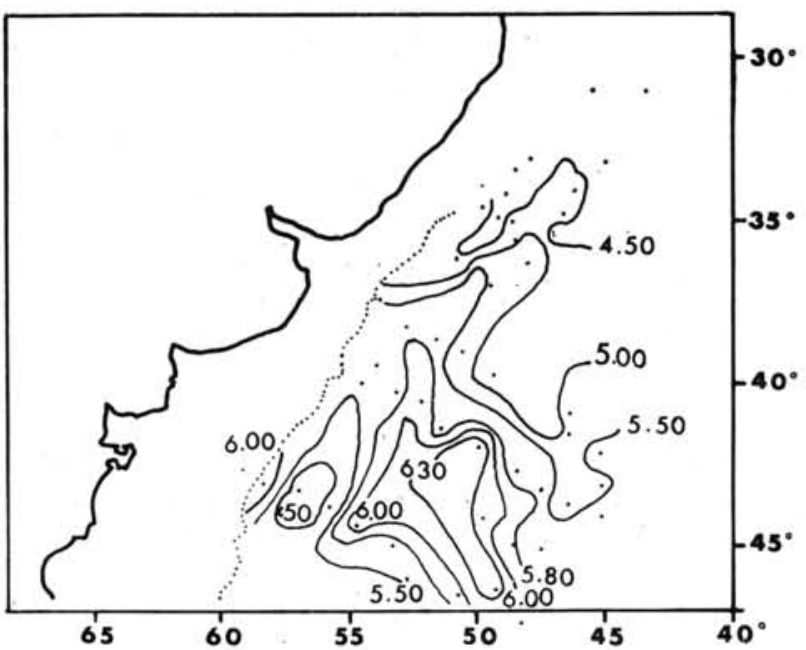

Fig. 19 - Distribución de oxigeno al nivel de 600 metros durante el invierno.

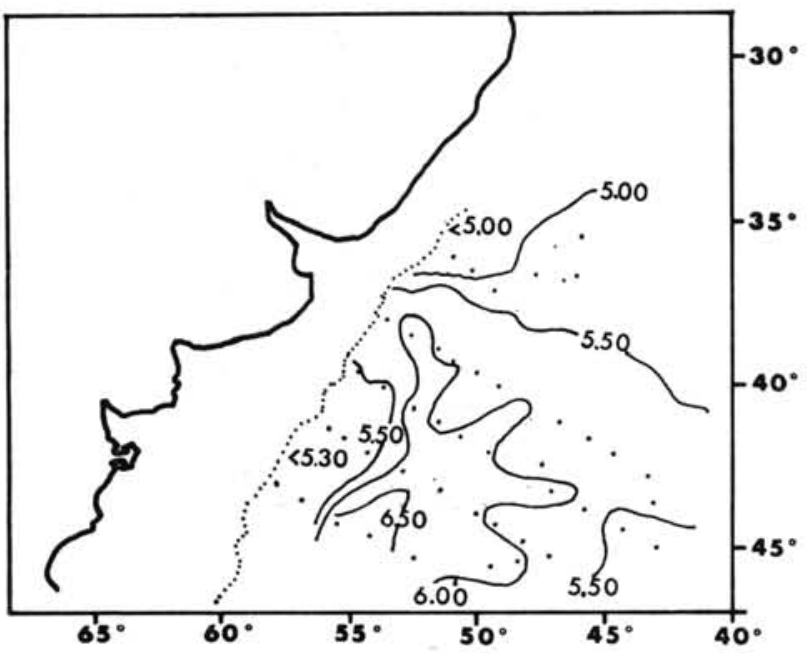

Fig. 20 - Distribución de oxígeno al nivel de 600 metros durante la primavera.

La distribución de salinidad en primavera, indicada en la Figura 20, nos muestra aguas con salinidades superiores a las vistas en invierno. Al norte sobre el área brasileña, se notan salinidades altas, algo mayor de $35,00^{\circ} / 00$, índice de la presencia de aguas subtropicales. Hacia el sur, la isohalina de $34,30^{\circ} \%_{00}$ indica la presencia de aguas de marcada influencia subantártica.

Sobre el costado oeste, al sud de los $41^{\circ} \mathrm{S}$, se presentan aguas de salinidades superiores a $34,30 \%$. Esta área que ectá limitada por la línea de $5,50 \mathrm{ml} / \mathrm{l}$ de oxígeno (Fig. 20) presenta temperaturas inferiores $2,70^{\circ} \mathrm{C}$, lo que es índice, junto con el tenor de oxígeno, de influencia de la masa CP. En la estación 414 la salinidad observada fué de $34,40^{\circ} \%$ con $6,70^{\circ} \mathrm{C}$, aquí la influencia es subtropical, es el último vestígio del gran núcleo de agua subtropical que encontramos en esta parte (Fig. 27, corte vertical).
Aquí la influencia subtropical en la mezcla, es la máxima observada, llegando a $50 \%$. Podemos deducir también de este hecho, que nos entramos en esta estación, por arriba del núcleo del agua subantártica, en cambio en la zona oeste, el núcleo del ASA esta más arriba. En este aspecto estriba la diferencia que existe en las condiciones de primavera e invierno. El hecho de encontrar en primavera puntos donde estamos aún por encima del núcleo del agua subantártica, apoya la hipótesis de que ésta capa está más hundida en primavera que en invierno.

La distribución de oxígeno en primavera indica que concentraciones de oxígeno superiores a $6,00 \mathrm{ml} / \mathrm{l}$ están en correspondencia con salinidades alrededor de $34,25 \%$. El área correspondiente a la influencia del APC, muestra un tenor superior de oxígeno al visto en invierno, índice de una mayor influencia de las aguas subantárticas en los procesos de mezcla.

\section{e) Oxígeno al nivel de 800 metros}

La distribución de oxígeno al nivel de 800 metros de profundidad en inviernos (Fig. 21) muestra nuevamente los máximos de ésta variable en la zona central del área estudiada. Esta área se encuentra ahora flanqueada por dos zonas de concentración de oxígeno menor. Las concentraciones menores de $5 \mathrm{ml} / 1$ de oxígeno tienen su origen, como ya vimos, en la influencia de las aguas cálidas profundas, que el aumentar la profundidad se hace naturalmente más marcada. La máxima influencia de las aguas subantárticas está indicada en el área encerrada por la isolinea de $5,70 \mathrm{ml} / 1$ de oxígeno.

La distribución de oxígeno en esta época nos demuestra también que estamos, al sud de los $37^{\circ} \mathrm{S}$, francamente por debajo del núcleo de las aguas subantárticas. La distribución en primavera, que se muestra en la Figura 22, también no está indicando lo mismo, aunque el hecho de observarse una área más extensa con concentraciones de oxígeno superiores a $6,00 \mathrm{ml} / \mathrm{l}$, es un índice de que estamos más cerca del núcleo de las aguas subantárticas que en el invierno. En apoyo a ésto no observamos la influencia de aguas profundas sobre la zona este.

$\mathrm{Al}$ norte de los $37^{\circ} \mathrm{S}$, la presencia de aguas subantárticas está reflejada en las concentraciones de oxígeno, las cuales llegan a $5,20 \mathrm{ml} / \mathrm{l}$, que son las concentraciones más altas (subsuperficiales) encontradas al norte de $37^{\circ} \mathrm{S}$. Este hecho indica que el núcleo de las aguas subantárticas debe estar cercano a este nivel pero a profundidad un poco mayor.

\section{f) La Salinidad y Oxigeno al nivel de 1000 metros}

La salinidad en el invierno a 1.000 metros de profundidad (Fig. 23) demuestra que nos encontramos francamente por debajo del núcleo del ASA. Las salinidades más bajas son alrededor de $34,25 \%$ y se situan al norte de los $40^{\circ} \mathrm{S}$. En esta área se 


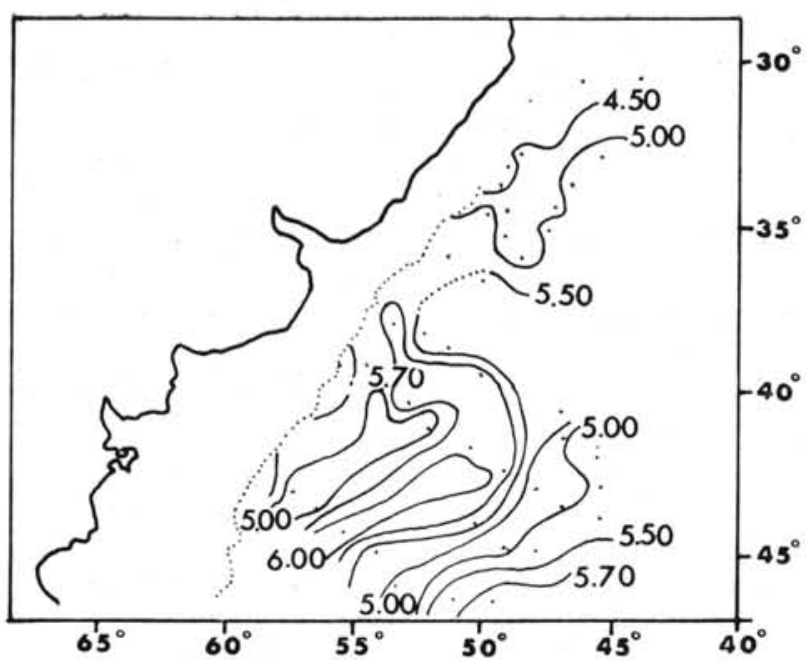

Fig. 21 - Distribución le oxígeno al nivel de 800 metros durante el invierno.

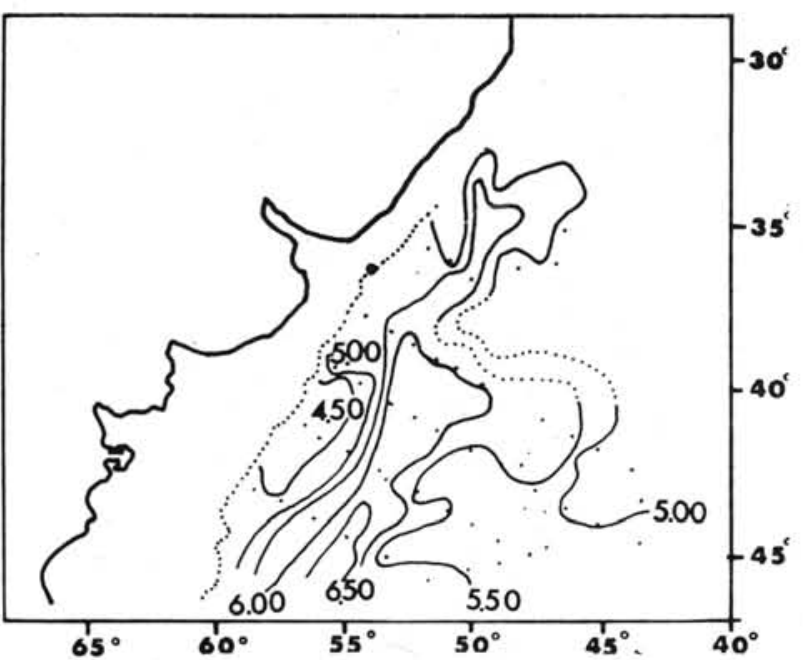

Fig. 22 - Distribución de oxigeno al nivel de 800 metros durante la primavera.

encuentra la mayor influencia de las aguas intermedias (ASA). Las salinidades máximas, 34,50\%, indican ahora una influencia muy marcada de las aguas $\mathrm{CP}$.

La distribución de oxígeno en invierno, que se ha dibujado en la Figura 25, muestra la gran influencia de las aguas profundas al sud de los $42^{\circ} \mathrm{S}$, en el área donde la concentración de oxígeno es menor de $5,00 \mathrm{ml} / \mathrm{l}$. Las máximas concentraciones se presentan, como es de esperar, en las áreas de baja salinidad. Al norte de $\operatorname{los} 37^{\circ} \mathrm{S}$, en la zona brasileña, observamos que el contenido de oxígeno es menor que el observado a 800 metros, de ello podemos deducir que el nucleo del agua intermedia (ASA) debe estar cercano a esta profundidad. Los datos del 'Atlantis' (F LugisTer, op cit.) indican un mínimo de salinidad alrededor de 950 metros a los $32^{\circ} \mathrm{S}$, es decir, unas 200 millas más al norte. Por lo tanto estimamos que la profundidad del nucleo del agua intermedia a los $35^{\circ} \mathrm{S}$, debe estar más cerca de 800 metros que de 1.000 metros, a juzgar por el contenido de oxígeno en ambos niveles.

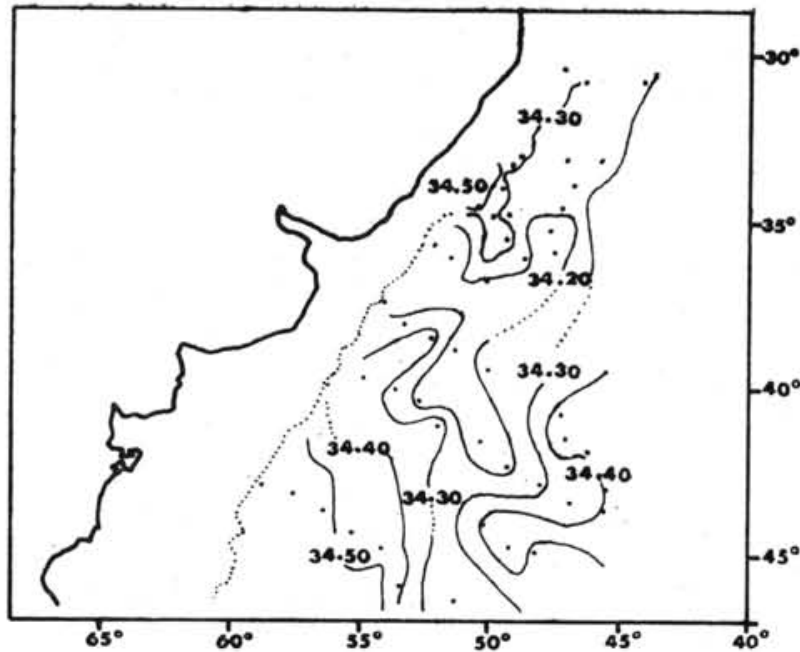

Fig. 23 - Isohalinas al nivel de 1000 metros durante el invierno.

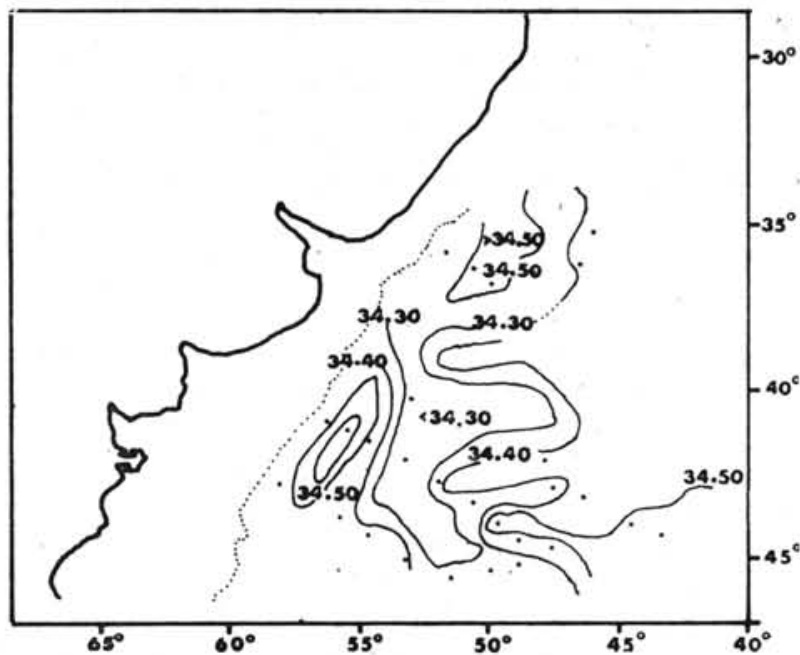

Fig. 24 - Isohalinas al nivel de 1000 metros durante la primavera.

Las condiciones observadas en primavera (Figs. 24. y 26) muestran las salinidades mínimas algo superiores a las vistas en invierno, además se situan un poco más al sur. La concentración de oxígeno correspondiente a esta área, presenta un tenor de oxígeno similar al de invierno, pero la zona es más extensa, coincidiendo con la de baja salinidad. En el área brasileña, las concentraciones de oxígeno son algo superiores a las vistas en invierno. Coincidiendo con el sector donde la salinidad es menor de $34,30^{\circ} /{ }_{00}$, la concentración de oxígeno es superior a $5,00 \mathrm{ml} / \mathrm{l}$. El área correspondiente a bajo contenido de oxígeno coincide también con alta salinidad.

\section{5 - Análisis de Perfiles Verticales}

En las Figuras 27 a 30 se presentan cuatro perfiles verticales Oeste-Este, a la latitud media de $41^{\circ} \mathrm{S}$, a fin de mostrar la distribución en profundidad de las variables salinidad y oxígeno para invierno y primavera. En las Figuras 1 y 2 se indican la posición de estos perfiles para invierno y 


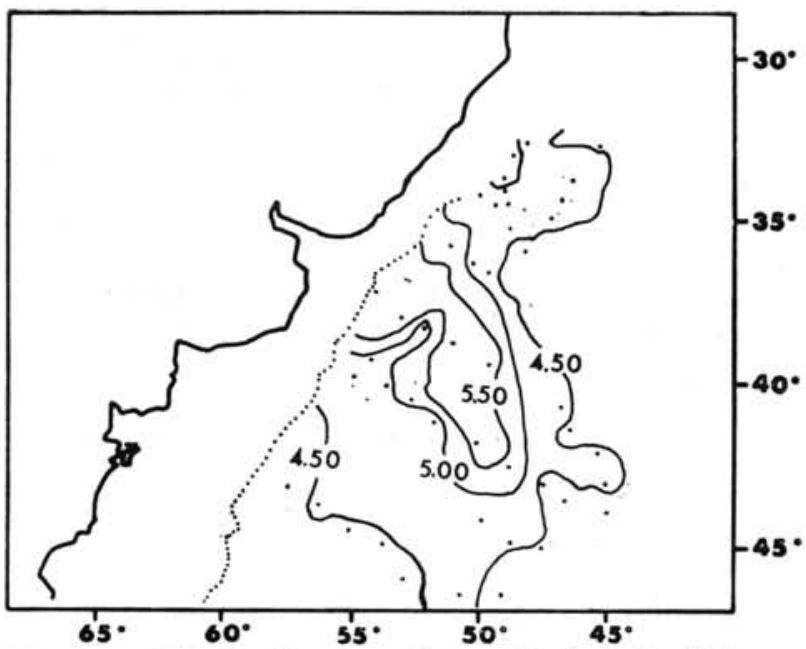

Fig. 25 - Distribución de oxigeno al nivel de 1000 metros durante el invierno.

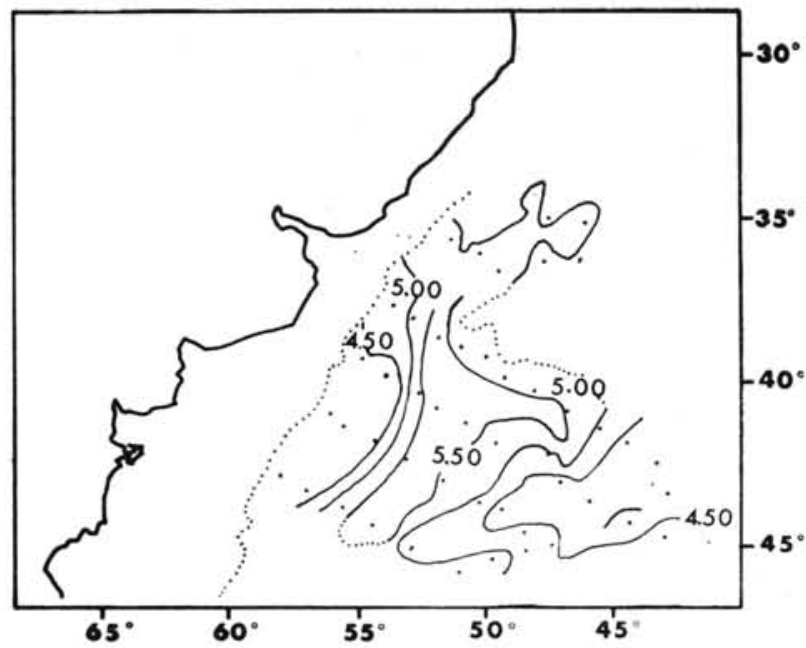

Fig. 26 - Distribución de oxigeno al nivel de $1000 \mathrm{me}$ tros durante la primavera.

primavera y las estaciones utilizadas para los mismos.

En la Figura 27 se ve la distribución de las isohalinas durante el invierno. Sobre el extremo izquierdo (oeste), se observa la mínima salinidad casi en superficie, es decir, un corte transversal de la corriente de Malvinas. Hacia el este, alrededor los $54^{\circ} 30 \mathrm{~W}$ (indicado en gráfico mediante una flecha vertical), se presenta la Convergencia Subtropical caracterizada por las isohalinas casi vertical desde la superficie hasta alrededor de 300 metros de profundidad.

Luego se encuentra un corte transversal a una rama de avance hacia el sud de la corriente de Brasil (aguas subtropicales), con salinidades muy superiores a $35,00^{\circ} \%$. Hacia los $51^{\circ} \mathrm{W}$, se presenta otro corte similar a otra rama de avance, pero más intensa que la anterior a juzgar por la profundidad de la misma y por valores de salinidad máximos de $35,80^{\circ} \%$. Entre ambos cortes se observa una área muy influenciada por las aguas subtropicales. Al este de los $47^{\circ} \mathrm{W}$, la influencia de las aguas subantárticas es más manifiesta.
El nucleo de la capa de agua subantártica está indicado mediante la linea de puntos que muestra la profundidad a que se encuentra la salinidad mínima. El rayado vertical indica las aguas cuya salinidad es menor de $34,20^{\circ} / 00$, o sea de acuerdo con la recta $\mathrm{B}$ de la Figura 3 , aguas subantárticas cuyo contenido de componente original es mayor de $65 \%$.

Se observan también en perfil que estamos analisando (invierno), tres cortes transversales a otras tantas ramas principales de avance hacia el norte de las aguas subantárticas. La primera de ellas, correspondiente a la corriente de Malvinas en superficie, con salinidades compreendidas entre 34,10 y $34,15^{\circ} \%$. En la parte central, hacia los $51^{\circ} 30^{\prime} \mathrm{W}$, alrededor de 400 metros de profundidad con una salinidad mínima de $34,14 \%$ y finalmente hacia el extremo este se presenta otro corte a una rama importante si tenemos en cuenta el área cubierta por la isohalina de $34,15 \%$. El núcleo se centra entre 500 y 600 metros de profundidad con una salinidad mínima de $34,13 \%$.

La influencia del ACP se comienza a notar por debajo de las ASA por la presencia de salinidad superiores a $34,30^{\circ} \%$. El núcleo del ACP de acuerdo con Wüst (1936), está caracterizado a los $50^{\circ} \mathrm{S}$ por $34,73 \%$ de salinidad y una temperatura de $1,65^{\circ} \mathrm{C}$. Teniendo en cuenta estas características y las del núcleo del ASA en sus orígenes $\left(33,80^{\circ} \%\right.$ de salinidad y $2,2^{\circ} \mathrm{C}$ de temperatura), y la expressión dada por Defant (1961, p. 204), deducimos que aguas con salinidades superiores a $34,30 \%$ a profundidades superiores a la del núcleo del ASA, son índice de una aporte de ACP superior al $50 \%$.

Las caracteristícas que presenta la distribución vertical de las isohalinas en primavera se han dibujado en la Figura 26. La comparación de los detalles que muestra esta figura con la que acabamos de ver correspondiente al invierno, hacen resaltar algunas diferencias de interés. En primer lugar la posición de la Convergencia en superfície se ha desplazado hacia el este con respecto a la que tenía en el invierno. En la Figura 28 se indica mediante una flecha vertical (trazo lleno) la posición de la C.St. en esta época, una flecha similar (trazo punteado) indica donde se situaba durante el invierno. La distancia corresponde a unas 50 millas náuticas; este aumento del ancho de la corriente de Malvinas en superficie, trae aparejado una disminución de la profundidad de la misma, ya que observamos que las isohalinas de $34,30 \%$ se encuentran a menos profundidad (unos 400 a 500 metros más arriba) que la vista en invierno.

Hacia el este, se encuentra ahora un corte a una rama muy importante de la corriente de Brasil. El área de la sección transversal, así también como los valores de salinidad, nos indican que es ésta la principal rama de avance al sud de la corriente de Brasil.

Entre $47^{\circ}$ y $48^{\circ} \mathrm{W}$, se encuentra otra rama de la misma corriente. Entre ámbas las aguas superficiales están muy influenciadas por ellas.

Con respecto a las aguas subantárticas también encontramos dos hechos de interés, el primero de 
ellos es la diferencia de profundidad a que se situa el mínimo de salinidad y en segundo lugar, la disminución del espesor de la capa de mínima salinidad. La profundidad a la cual situa el núcleo de ASA depende del desplazamiento hacia el sud de las aguas de la corriente de Brasil. Durante la pri- mavera, la rama principal de la corriente de Brasil si situa entre $50^{\circ}$ y $52^{\circ} \mathrm{W}$, lo cual obliga a que el núcleo de las ASA se hunda unos 400 metros respecto a la profundidad que tenía en invierno. Entre los $47^{\circ} 30^{\prime}$ y $50^{\circ} \mathrm{W}$, en cambio la desaparición de la principal rama de avance de la corriente de

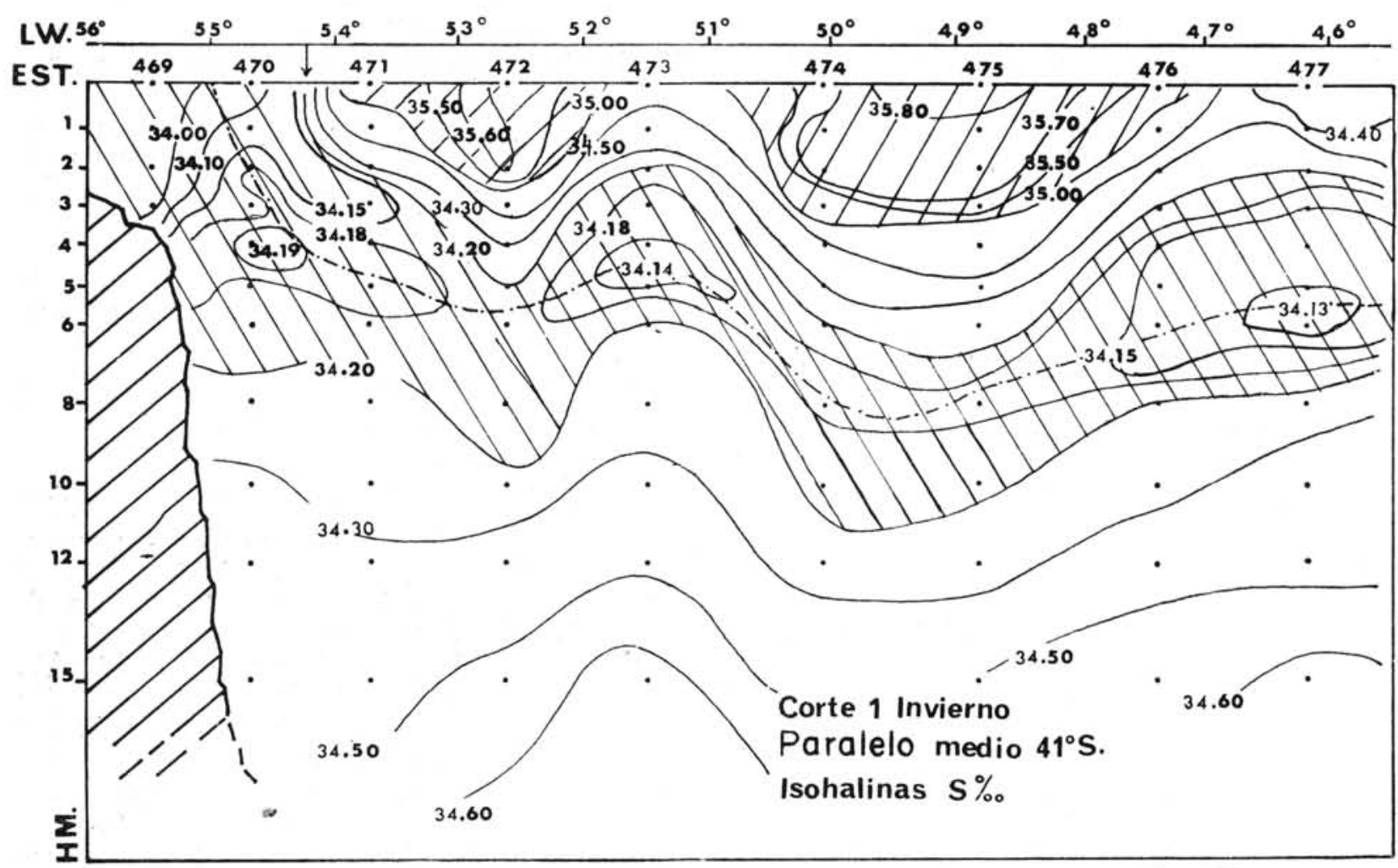

Fig. 27 - Distribución vertical de las isohalinas en un perfil W.E. Paralelo medio $41^{\circ}$ s.

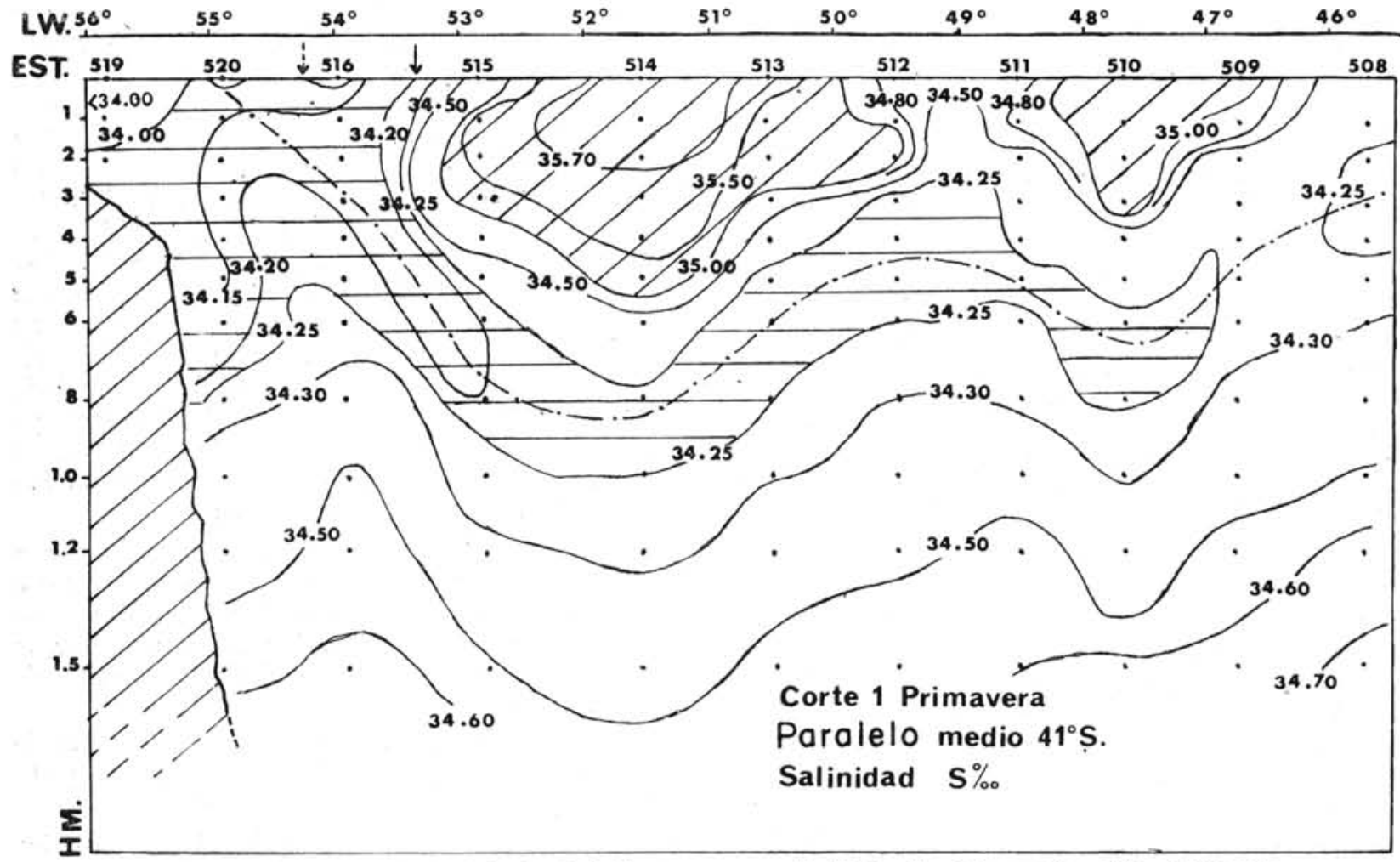

Fig. 28 - Distribución vertical de las isohalinas en un perfil W.E. Paralelo medio $41^{\circ}$ S. Primavera. 


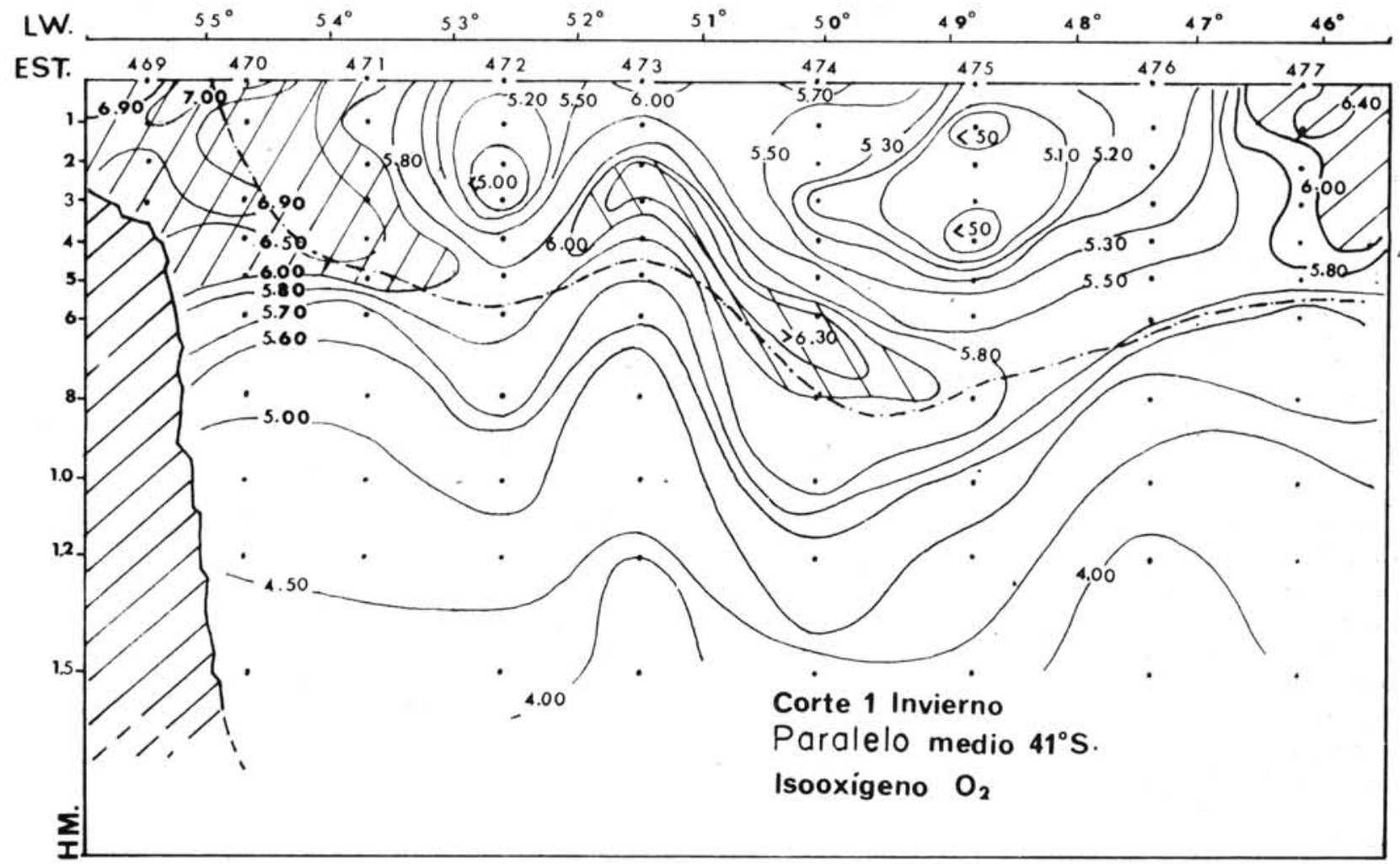

Fig. 29 - Distribución vertical de oxigeno en un perfil W-E. Paralelo medio $41^{\circ} \mathrm{L}$. Invierno.

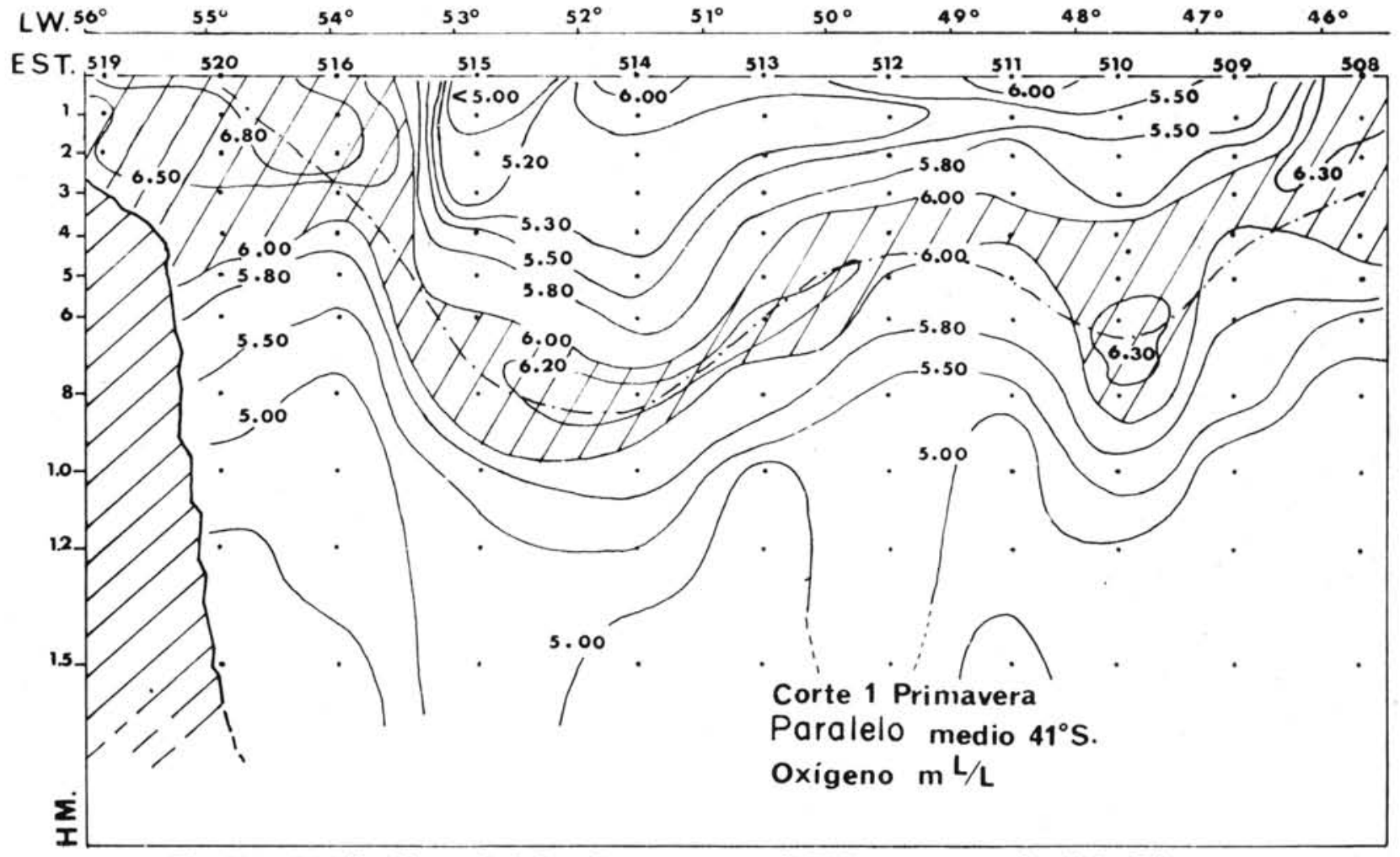

Fig. 30 - Distribución vertical de oxigeno en un perfil W-E. Paralelo medio $41^{\circ} \mathrm{S}$. Primavera.

Brasil por esa zona, hace que el núcleo de las SAS, remote unos 400 metros, respecto a la profundidad en el invierno. Hacia el extremo derecho del dibujo la posición del mínimo de salinidad también presenta una oscilación con respecto al invierno, pero de menor amplitud, unos 200 metros.
El espesor de la capa de ASA, considerando entre las isohalinas de $34,20^{\circ} \%$, es bastante menor en primavera. Los mínimos de salinidad son superiores en esta época, practicamente toda la capa ASA, presenta salinidades comprendidas entre 34,20 y $34,25 \%$. 
Valores menores de $34,20^{\circ} \%$, se reducen a la zona oeste. Al discutir la distribución de oxígeno, presentamos una explicación para este detalle.

Por debajo de las ASA, las ACP hacen sentir su influencia, la cual es posible de deducir en base al aumento de salinidad.

Esta capa también sigue las mismas oscilacio. nes que presenta la capa intermedia, siendo más notable su influencia en el costado oeste; el mínimo de salinidad a las ASA está en superficie o muy cercano a ella.

En las Figuras 29 y 30 , se han dibujado las líneas de isoconcentración de oxígeno en los mismos perfiles que acabamos de ver para salinidad. La Figura 29 se refiere al invierno y 30 a la primavera.

La primera característica que resalta a observar estos dos cortes, es la mayor concentración de oxígeno en primavera. Los dos núcleos de aguas subtropicales (corriente de Brasil), solamente en invierno presentan concentraciones de oxígeno menor de $5,0 \mathrm{ml} / \mathrm{l}$; en primavera, en cambio, los valores son mayores, hasta 800 metros de profundidad. Las máximas concentraciones de oxígeno se presentan como ya habíamos hecho notar, sobre la zona de la corriente de Malvinas.

En invierno observamos tres zonas bien definidas con altas concentraciones de oxígeno. Una sobre el costado oeste, desde la superfície hasta 500 metros de profundidad, las concentraciones son siem. pre superiores a $6,00 \mathrm{ml} / \mathrm{l}$ de oxígeno. Hacia la parte central entre $49^{\circ}$ y $52^{\circ} \mathrm{W}$ se situa una área de concentraciones de oxígeno mayores de $6.00 \mathrm{ml} / \mathrm{l}$ (rayado en la figura) y finalmente hacia el extremo este sobre la superfície observamos la tercera zona.

Los cortes a las ramas de la corriente de Brasil están asociados a concentraciones de oxígeno inferiores a $5,20 \mathrm{ml} / \mathrm{l}$.

Los máximos de oxígeno no coinciden con la profundidad adonde se encuentra la mínima salinidad, salvo sobre la parte oeste del perfil. La línea punteada indica que los máximos de oxígeno se situan por arriba de la profundidad del núcleo del ASA. La isolinea de $5.00 \mathrm{ml} / \mathrm{l}$ de oxígeno puede considerar-se aproximadamente con el mismo significado de la isohalina de $34,30^{\circ} \%$, es decir, la influencia de las ACP, con concentraciones de oxígeno regularmente inferiores a $5 \mathrm{ml} / \mathrm{l}$ de oxígeno.

En primavera, como ya vimos al tratar los cortes horizontales están asociados a concentraciones inferiores a $5,70 \mathrm{ml} / \mathrm{l}$ de oxígeno. La mínima salinidad presenta en esta época una correlación con la profundidad adonde se encuentra el máximo de oxígeno.

En esta época del año y a esta latitud, la capa inmedia (ASA) está limitada por la isohalina de $34,25 \%$, las isolineas de $6,00 \mathrm{ml} / 1$ de oxígeno se extienden casi paralelas a aquellas en todo lo ancho del perfil limitando un área, con oxígeno superior a $6,00 \mathrm{ml} / \mathrm{l}$ de oxígeno, considerablemente superior a la vista en invierno. No solamente esta área sino también la que limitan las isolineas de $5,50 \mathrm{ml} / \mathrm{l}$ de oxígeno es superior en primavera a la vista en invierno. Estos detalles así también como la mayor salinidad en el núcleo de las aguas intermedias (ASA), llama la atención, la hipótesis que planteamos para explicar estos hechos es la seguiente. $\mathrm{Si}$ observamos la Figura 4, notamos que la Convergencia Subtropical en invierno, se situa aproximadamente coincidente con la latitud media del corte vertical que analisamos. En primavera en cambio (Fig. 6), el mismo fenómeno se encuentra más al sud, alrededor de los $44^{\circ} \mathrm{S}$. De esto deducimos que las aguas subantárticas intermedias que encontramos en invierno, no han recibido aún el aporte de las aguas subantárticas que se hunden en la convergencia de allí su bajo tenor salino y su relativamente pobre contenido en oxígeno. La situación en primavera nos indica la presencia de aguas subantárticas más recientemente hundidas, lo cual in. dicado en su salinidad algo mayor que invierno y en su contenido de oxígeno. El hecho de hallar los máximos de oxígeno por arriba de los mínimos de salinidad en el invierno, puede ser una indicación del comienzo de un fenómeno a esta latitud que se acentúa más al norte y que se acentuará a esta misma latitud, más entrado el año: el aporte de agua subantártica superficial.

Una confirmación o, un apoyo a lo que acabamos de sostener, lo encontramos en el hecho de que la bolsa de máximo oxígeno que observamos en invierno se encuentran precisamente por debajo de los núcleos de aguas subtropicales y sobre el extremo este, encontramos aguas con oxígeno relativa. mente alto, directamente en superficie. En el primer caso, la Convergencia ya ha tenido lugar, en el segundo caso son aguas subantárticas que aún se han hundido.

En primavera las aguas subtropicales ocupan casi toda la zona superficial, salvo en el costado oeste, hasta profundidades medias de 500 metros, es decir que practicamente toda el agua subantártica está ya hundida (norte de la Convergencia) y muy recientemente, de allí su tenor alto en oxígeno y su mayor salinidad con respecto al invierno.

Podríamos decir también que la situación que se observa en el corte de primavera, podría pertenecer al invierno, pero más al norte, o bien que él corte invernal podria presentarse en primavera, pero más al sur.

Teniendo em cuenta el desplazamiento que presenta la Convergencia Subtropical entre el invierno (mes de Agosto) y la primavera (mes de Diciem. bre), unas 200 millas náuticas, podemos hacer una estima de la velocidad de transporte de la corriente de Brasil, que nos da unas 100 millas mensuales, o sea $5,0 \mathrm{~cm} / \mathrm{s}(0,10$ nudos $)$.

\section{AGRADECIMIENTO}

Queremos dejar sentado nuestro agradecimiento al Prof. Dr. Nicanor Menendez García, por sus sugerencias y consejos que fueron fundamentales para la elaboración de este trabajo.

Agradecemos también a los señores Salanouve, Morales y D'Anunzio por la preparación de las tablas de valores y gráficos. 
Brasil. Ministério da Marinha. Diretoria de Hidrografia e NaVegação.

1963a. Operação oceanográfica Tridente I. D.H.N.-DG-06-XV, 21 p.

1963b. Operação oceanográfica Tridente II. D.H.N.-DG-06-XVI.

Capurro, L. R. A.

1955. Expediciones oceanográficas actuales en el Mar Epicontinental Argentino. Argentina, Direcc. gen. Nav. Hidr.

DeAcon, G. E. R.

1933. A general account of the hydrology of the south Atlantic Ocean. 'Discovery' Rep., vol. 7, p. 171-238.

Defant, A.

1961. Physical oceanography. Londres, Pergamon Press, vol. 1, p. 1-279.

Discovery COMMTTTEE. LONDON

1941. Station list, 1931-1933. 'Discovery' Rep., vol. 21 , p. $1-226$, pl. I-IV.

Fuglister, F. C.

1960. Atlantic Ocean atlas of temperature and salinity profiles and data from the International Geophysical Year of 19571958. Woods Hole oceanogr. Instn Atlas Ser., vol. 1, 209 p.
LusQuiÑos, A.

1966. Determinación de la Convergence Subtropical sobre la base de los datos de temperatura y salinidad obtenidos en las Campañas Tridente I y II. Boln Serv. Hidr. Naval, vol 3, n. ${ }^{\circ}$ 2, p. 79-98.

Menéndez, N. \& Pizarro, M. J.

1965. Study of the oceanographic structure along the $30^{\circ} \mathrm{W}$ meridian in the south Atlantic. Anais Acad. bras. Ciênc., vol. 37, supl., p. 95-108.

SAYED, Z. El-SAYed

1964. Primary production and standing crop of phytoplankton along the Argentinian coast, Drake Passage and Brandfield Strait. Texas A \& M University, ref. n. ${ }^{\circ} 64-9 A$, p. 1-76.

Truesdale, G. A. Downing, A. L. \& Lowdeb, G. F. 1955. Determination of the solubility of the oxygen in fresh water and sea water. J. appl. Chem. Lond., vol. 5, p. 53-59.

WüsT, G. 1936.

Die Strastophäre des Atlantischen Ozeans. Deutsche Atlantische Expedition 'Meteor', 1925-1927. Wiss. Ergebn. dt. atlant. Exped. 'Meteor', vol. 6. p. 163. 